\title{
Prevalence and risk factors of allergic rhinitis in children in Bangkok area
}

\author{
Sasawan Chinratanapisit, ${ }^{1}$ Narissara Suratannon, ${ }^{2}$ Punchama Pacharn, ${ }^{3}$ Paskorn Sritipsukho,${ }^{4,5}$ Pakit Vichyanond ${ }^{3}$
}

\begin{abstract}
Background: Allergic rhinitis (AR) is a disease with a high global disease burden and significant morbidity and expense. Risk factors are not well understood.
\end{abstract}

Objective: The objective of our project is to study the prevalence and risk factors of AR in children living in the Bangkok area.

Methods: A cross-sectional, multi-center survey using new GAN core questionnaires on current AR and risk factors was completed by 3,074 parents of children aged 6-7 years and by 3,217 children aged 13-14 years, directly.

Results: The prevalence of current AR in children aged 6-7 years and 13-14 years was 15.0\% (95\% confidence interval [CI]:13.8-16.3\%) and 17.5\% (95\% CI: 16.2-18.8\%), respectively. The prevalence of severe AR in children aged 6-7 years and 13-14 years was 1.0\% (95\% CI: 0.6-1.3\%) and 1.9\% (95\% CI: 1.4-2.4\%), respectively. Co-morbidity with asthma and eczema was $27.1 \%$ and $24.6 \%$, respectively. Significant factors associated with AR include parental history of asthma ( $\mathrm{p}=$ 0.025), parental history of AR ( $p<0.001)$, parental history of eczema $(\mathrm{p}<0.001)$, lower respiratory tract infection in the first year of life $(\mathrm{p}<0.001)$, breastfeeding $(\mathrm{p}=0.019)$, current use of paracetamol $(\mathrm{p}<0.001)$, exercise $(\mathrm{p}<0.001)$, current cat exposure $(\mathrm{p}=0.008)$, and truck traffic on the street of residence $(<0.001)$.

Conclusion: AR is a common disease among children residing in Bangkok. This study confirms that a family history of atopy (asthma, AR, and eczema), antibiotics given in the first year of life, current paracetamol use, exercise, current cat exposure, and truck traffic on the street of residence are important and significant risk factors for AR symptoms.

Key words: allergic rhinitis, atopy, asthma, ISAAC, GAN

\section{From:}

${ }^{1}$ Department of Pediatrics, Bhumibol Adulyadej Hospital, Royal Thai Air Force, Bangkok, Thailand

${ }^{2}$ Pediatric Allergy \& Clinical Immunology Research Unit, Division of Allergy and Immunology, Department of Pediatrics, Faculty of Medicine, Chulalongkorn University, King Chulalongkorn Memorial Hospital, the Thai Red Cross Society, Bangkok, Thailand

Division of Allergy and Immunology, Department of Pediatrics, Faculty of Medicine, Siriraj Hospital, Mahidol University, Bangkok, Thailand

${ }^{4}$ Center of Excellence in Applied Epidemiology, Thammasat University, Pathum Thani, Thailand

Allergy Unit, Department of Pediatrics, Faculty of Medicine,

Thammasat University, Pathum Thani, Thailand

\section{Corresponding author:}

Paskorn Sritipsukho

Department of Pediatrics, Faculty of Medicine, Thammasat University,

Pathum Thani, Thailand

E-mail: paskorn100@yahoo.com

\section{Introduction}

Allergic rhinitis (AR) is characterized by paroxysms of sneezing, rhinorrhea, and nasal obstruction, often accompanied by itching of the eyes, nose, and palate. Postnasal drip, cough, irritability, and fatigue are other common symptoms. ${ }^{1,2}$ $\mathrm{AR}$ is associated with significant morbidity and expense. ${ }^{3,4}$

The increase in the prevalence of AR began to attract attention from epidemiologists in the late 1980s. The International Study of Asthma and Allergies in Childhood (ISAAC) was initiated to establish the prevalence of allergic diseases in 257,800 school children aged 6-7 years and in 463,801 children aged 13-14 years using standardized and validated questionnaires. ${ }^{7}$ Phase I of ISAAC, which began to enroll patients in 1992, sought to establish prevalence rates in nearly 60 countries on every continent; phase II investigated variables contributing to AR (e.g., environmental exposures); and phase III provided follow-up data on the patients at least five years after entry into the study. In phase I, prevalence rates for AR collected across all centers ranged from $0.8 \%$ to $14.9 \%$ (median, $6.9 \%$ ) 
in the $6-7$-year-olds and from $1.4 \%$ to $39.7 \%$ (median, $13.6 \%$ ) in the 13-14-year-olds. ${ }^{5}$ The highest prevalence rates for AR were observed in parts of Western Europe, North America, and Australia, whereas the lowest rates were found in parts of Eastern Europe and South and Central Asia. The phase III analyses revealed that the prevalence rates had increased, with 12 -month prevalence rates of $1.8 \%$ to $24.2 \%$ in children aged 6-7 years (median, $8.5 \%$ ) and $1.0 \%$ to $45 \%$ (median, $14.6 \%$ ) in children aged $13-14$ years. ${ }^{6}$ These findings strongly indicate that the prevalence of AR has increased over a relatively short period of time, mostly in Westernized countries with a higher standard of living.

According to phase I of ISAAC in Bangkok (1995-1999), the prevalence of AR was $10.0 \%$ in the children aged 6-7 years and $15.4 \%$ in the children aged $13-14$ years. ${ }^{7}$ In phase III of the study in Bangkok (2001), the prevalence of AR in children aged 6-7 years and $13-14$ years was $13.4 \%$ and $23.9 \%$, respectively. ${ }^{8}$ There was an increase in the prevalence of rhinitis in both age groups.

Phase III of ISAAC included new questions on risk factors that identified several environmental associations. ${ }^{9}$ Risk factors for AR include paracetamol, antibiotics, truck traffic, breastfeeding, farm animals, cats and dogs, air pollution, tobacco, body mass index (BMI), diet, cooking fuels, birth weight, migration, and siblings. Despite the considerable research efforts, the risk factors of AR remain poorly understood. A family history of atopic diseases seems to be a major risk factor, but various environmental factors and lifestyle are also considered important elements in the evolution of the disease. ${ }^{3,10}$

The objective of our project is to study the prevalence and risk factors of AR in children living in Bangkok, Thailand.

\section{Methods \\ Study Design}

This study has a cross-sectional, multi-center design.

\section{Participants}

Seven primary schools and six secondary schools in Bangkok were randomly mapped, stratified, and chosen to represent the population of the entire Bangkok metropolitan area. Subjects were selected in the same manner as ISAAC phase III. ${ }^{9}$ The same age groups were recruited: 13-14-year-old children (self-completed questionnaires) and 6-7-year-old children (parental completed questionnaires). Of 6,834 questionnaires sent to children, 6,291 were completed (95.05\%). There were 3,074 (86.49\%) questionnaires of children aged 6-7 years and 3,217 (98.08\%) questionnaires of children aged 13-14 years available for analysis. The study was approved by the Human Research Ethics Committee of Thammasat University (054/2560) and the Human Research Ethics Committee of Bhumibol Adulyadej Hospital. The clinical trial number was MTU-EC-ES-4-013/60. Informed consents/assents were obtained from the children and parents.

\section{GAN Core Questionnaires}

GAN 2016 standardized written core questionnaires for AR modifying from ISAAC questionnaires were used in this study. ${ }^{11,12}$ The questionnaires were translated and back-translated into the Thai language by three independent linguistic -proficient individuals. Demographic questions included the participant's name, age, date of birth, school (for the adolescents and children), sex, and date of interview. Questionnaires were coded by using a unique number for each center, school, and participant to ensure confidentiality and to link the questionnaires between the adults and children. ${ }^{13}$ The written core questionnaires, used in GAN, had a question about doctor-diagnosed asthma, rhinitis, and eczema added. The core questions were both sensitive and specific, and they had good content, construct, concurrent, and predictive validity. ${ }^{14}$ The environmental risk factor questionnaires, developed for ISAAC phase III, were expanded for use in this study. Height and weight measurements were taken by the fieldworkers in schools.

\section{Definitions of AR, Rhinitis, and Hay Fever}

The standardized core symptom questionnaire was the same as that used in ISAAC phase I and comprised of six questions on symptoms relating to rhinitis or rhinoconjunctivitis. ${ }^{11,12}$ These questions were as follows:

1. Have you (has your child) ever had a problem with sneezing or a runny or blocked nose when you (he or she) DID NOT have a cold or "the flu"?

2. In the past 12 months, have you (has your child) had a problem with sneezing or a runny or blocked nose when you (he or she) DID NOT have a cold or "the flu"?

3. In the past 12 months, has this nose problem been accompanied by itchy/watery eyes?

4. In which of the past 12 months did this nose problem occur? (Month names listed)

5. In the past 12 months, how much did this nose problem interfere with your (child's) daily activities? (Not at all, a little, a moderate amount, a lot)

6. Have you (has your child) ever had hay fever?

Question 2 was used to estimate the prevalence of current rhinitis; question 3 was used to estimate the prevalence of current conjunctivitis; and question 6 was used to estimate the prevalence of "hay fever ever." Questions 2 and 3 were combined to assess current rhinoconjunctivitis symptoms or current AR. Questions 2 and 3 and the answer "A LOT" to question 5 were used to assess the prevalence of severe rhinoconjunctivitis symptoms or severe AR.

\section{Sample Size}

A sample size of 2,654 is needed to estimate the prevalence of questionnaire-based AR of $10 \%$ for children of each age group with margin errors of $\pm 1.5 \%$ and type one error of 0.01 . The total sample size of 6,834 was accounted for the non-response rate of $30 \%$.

\section{Data Collection and Analysis}

Data were collected from July 2017 to February 2018. Statistical analyses were carried out using STATA/SE software (Stata/SE 14 for Windows, StataCorp LP, College Station, TX, USA). Binomial confidence intervals (CIs) on proportions with rhinitis and rhinoconjunctivitis were calculated. The multivariable logistic regression model was used to conduct exploratory analysis for risk factors of AR. The model included 
age, sex, family history of allergy, birth weight, paracetamol, antibiotics, truck traffic, breastfeeding, farm animals, cat and dog exposure, air pollution, tobacco, BMI, diet, cooking fuels, migration, and number of older and younger siblings to estimate the magnitude of the association by calculating adjusted odds ratios with their $95 \%$ CIs.

\section{Results}

The prevalence of questionnaire-based symptoms of rhinitis stratified by age group is shown in Table 1 . The prevalence of current rhinitis in children aged 6-7 years and 13-14 years was $38.2 \%$ (95\%CI: 36.5-39.9\%) and 48.8\% (95\%CI: $47.0-$ $50.5 \%)$, respectively. The prevalence of current rhinitis in all children was $43.6 \%$ (95\%CI: 42.4-44.8\%). Concomitant eye symptoms were reported at $16.3 \%$. The prevalence of current AR in children aged 6-7 years and 13-14 years was $15.0 \%$ (95\%CI: $13.8-16.3 \%)$ and $17.5 \%$ (95\%CI: $16.2-18.8 \%)$, respectively. The prevalence of current AR in all children was $16.3 \%$ (95\%CI: $15.4-17.2 \%)$.

Although the term so-called "hay fever" does not exist in the Thai language, $27.4 \%$ indicated that they suffered from "allergy to the air," a common term denoting hay fever in Thailand.
Patterns of rhinitis symptoms of children in Bangkok were of the perennial type. The prevalence of severe $\mathrm{AR}$ in children aged 6-7 years and 13-14 years was $1.0 \%$ (95\%CI: $0.6-1.3 \%$ ) and $1.9 \%$ (95\%CI: $1.4-2.4 \%)$, respectively. The prevalence of severe AR in all children was $1.5 \%$ (95\%CI: $1.2-1.7 \%)$. There were strong associations with other allergic diseases: $27.1 \%$ of children with AR had asthma and 24.6\% had eczema.

A parental history of atopy including asthma $(\mathrm{p}=0.025$, $\mathrm{OR}=1.50,95 \% \mathrm{CI}=1.05-2.13), \mathrm{AR}(\mathrm{p}<0.001, \mathrm{OR}=1.43$, $95 \% \mathrm{CI}=1.10-1.71)$, and eczema $(\mathrm{p}<0.01, \mathrm{OR}=1.56,95 \% \mathrm{CI}$ $=1.29-1.88)$ was significantly related to current AR. Current use of paracetamol was associated with current $A R(p<$ $0.001, \mathrm{OR}=1.64,95 \% \mathrm{CI}=1.30-2.08)$. Exercise was associated with current AR ( $\mathrm{p}<0.001, \mathrm{OR}=1.49,95 \% \mathrm{CI}=1.29-1.71)$. Only current cat exposure was associated with current AR $(\mathrm{p}=0.008, \mathrm{OR}=1.28,95 \% \mathrm{CI}=1.07-1.54)$. The frequency of truck traffic on the street of residence was positively associated with current AR; comparison of both the occasional truck traffic group $(\mathrm{p}=0.002, \mathrm{OR}=1.28,95 \% \mathrm{CI}=1.10-1.50)$ and the always truck traffic group $(\mathrm{p}<0.001$, OR $=1.73$, $95 \% \mathrm{CI}=1.41-2.11)$ to the never truck traffic group is shown in Tables 2 and 3.

Table 1. Prevalence of questionnaires-based symptoms of rhinitis stratified by age group

\begin{tabular}{|c|c|c|c|c|c|c|}
\hline \multirow[t]{2}{*}{ Symptoms } & \multicolumn{2}{|c|}{ All $(n=6,291)$} & \multicolumn{2}{|c|}{$6-7$ years $(n=3,074)$} & \multicolumn{2}{|c|}{$13-14$ years $(n=3,217)$} \\
\hline & $\mathbf{N}$ & $\begin{array}{c}\text { Prevalence } \\
95 \% \mathrm{CI}\end{array}$ & $\mathbf{N}$ & $\begin{array}{c}\text { Prevalence } \\
95 \% \mathrm{CI}\end{array}$ & $\mathbf{N}$ & $\begin{array}{c}\text { Prevalence } \\
95 \% \mathrm{CI}\end{array}$ \\
\hline Current AR or ARC & 1,042 & $\begin{array}{c}16.3 \% \\
(15.4 \%, 17.2 \%)\end{array}$ & 462 & $\begin{array}{c}15.0 \% \\
(13.8 \%, 16.3 \%)\end{array}$ & 580 & $\begin{array}{c}17.5 \\
(16.2 \%, 18.8 \%)\end{array}$ \\
\hline Current rhinitis & 2,744 & $\begin{array}{c}43.6 \% \\
(42.4 \%, 44.8 \%)\end{array}$ & 1,175 & $\begin{array}{c}38.2 \% \\
(36.5 \%, 39.9 \%)\end{array}$ & 1,569 & $\begin{array}{c}48.8 \% \\
(47.0 \%, 50.5 \%)\end{array}$ \\
\hline Hay fever (allergic to air) & 1,722 & $\begin{array}{c}27.4 \% \\
(26.3 \%, 28.5 \%)\end{array}$ & 754 & $\begin{array}{c}24.5 \% \\
(23.0 \%, 26.1 \%)\end{array}$ & 968 & $\begin{array}{c}30.1 \% \\
(28.5 \%, 31.7 \%)\end{array}$ \\
\hline Severe AR & 91 & $\begin{array}{c}1.5 \% \\
1.2 \%, 1.7 \%)\end{array}$ & 30 & $\begin{array}{c}1.0 \% \\
(0.6 \%, 1.3 \%)\end{array}$ & 61 & $\begin{array}{c}1.9 \% \\
(1.4 \%, 2.4 \%)\end{array}$ \\
\hline
\end{tabular}

Current AR or Allergic rhinoconjunctivitis (ARC)- positive to question number 2 and 3

Current rhinitis - positive to question number 2

Hay fever ever- positive to question number 6

Severe AR - positive to question number 2 and 3 and the answer "A LOT" to question 5

Table 2. Characteristics of children with AR stratified by age group

\begin{tabular}{|c|c|c|c|c|c|c|c|c|c|}
\hline \multirow[t]{2}{*}{ Factors } & \multicolumn{3}{|c|}{ Total $(n=6,291)$} & \multicolumn{3}{|c|}{ 6-7 Years old $(n=3,074)$} & \multicolumn{3}{|c|}{ 13-14 Years old $(n=3,217)$} \\
\hline & $\mathbf{N}$ & n (\%) & P-value & $\mathbf{N}$ & n (\%) & P-value & $\mathbf{N}$ & n (\%) & P-value \\
\hline Age (years) & & & 0.009 & & & & & & \\
\hline $6-7$ & 3,074 & $462(15.0)$ & & - & - & - & - & - & - \\
\hline $13-14$ & 3,217 & $562(17.5)$ & & - & - & - & - & - & - \\
\hline Sex & & & 0.143 & & & 0.023 & & & 0.760 \\
\hline Female & 3,013 & $468(15.6)$ & & 1,559 & $211(13.6)$ & & 1,454 & $257(17.7)$ & \\
\hline Male & 3,278 & $555(16.9)$ & & 1,515 & $250(16.5)$ & & 1,763 & $305(17.3)$ & \\
\hline BMI & & & 0.137 & & & 0.172 & & & 0.445 \\
\hline$<$ P85 & 5,360 & $857(16.0)$ & & 2,619 & $384(14.7)$ & & 2,471 & $473(17.3)$ & \\
\hline$\geq$ P85 & 931 & $167(17.9)$ & & 455 & $78(17.1)$ & & 476 & $89(18.7)$ & \\
\hline
\end{tabular}


Table 2. (Continued)

\begin{tabular}{|c|c|c|c|c|c|c|c|c|c|c|}
\hline \multirow[t]{2}{*}{ Factors } & & \multicolumn{3}{|c|}{ Total $(n=6,291)$} & \multicolumn{3}{|c|}{ 6-7 Years old $(n=3,074)$} & \multicolumn{3}{|c|}{ 13-14 Years old $(n=3,217)$} \\
\hline & & $\mathbf{N}$ & n (\%) & P-value & $\mathbf{N}$ & n (\%) & P-value & $\mathbf{N}$ & n (\%) & P-value \\
\hline \multicolumn{11}{|l|}{ Paternal allergy history } \\
\hline \multirow{2}{*}{ Asthma } & No & 6,107 & $976(16.0)$ & $<0.001$ & 2,965 & $434(14.6)$ & 0.002 & 3,142 & $542(17.3)$ & 0.034 \\
\hline & Yes & 184 & $48(26.1)$ & & 109 & $28(25.7)$ & & 75 & $20(26.7)$ & \\
\hline \multirow[t]{2}{*}{$\mathrm{AR}$} & No & 5,234 & $775(14.8)$ & $<0.001$ & 2,442 & $303(12.4)$ & $<0.001$ & 2,792 & $472(16.9)$ & 0.031 \\
\hline & Yes & 1,057 & $249(23.6)$ & & 632 & $159(25.2)$ & & 425 & $90(21.2)$ & \\
\hline \multirow[t]{2}{*}{ Atopic } & No & 5,434 & $811(14.9)$ & $<0.001$ & 2,595 & $331(12.8)$ & $<0.001$ & 2,839 & $480(16.9)$ & 0.021 \\
\hline & Yes & 857 & $213(24.9)$ & & 479 & $131(27.3)$ & & 378 & $82(21.7)$ & \\
\hline \multirow[t]{2}{*}{ Sibling } & No & 2,013 & $327(16.2)$ & 0.961 & 1,034 & $140(13.5)$ & 0.100 & 979 & $187(19.1)$ & 0.107 \\
\hline & Yes & 4,278 & $697(16.3)$ & & 2,040 & $322(15.8)$ & & 2,238 & $375(16.8)$ & \\
\hline \multicolumn{11}{|l|}{ Only 6-7 Years old } \\
\hline \multirow[t]{2}{*}{ LBW } & No & - & - & - & 2,830 & $423(14.9)$ & 0.664 & - & - & - \\
\hline & Yes & - & - & - & 224 & $39(16.0)$ & & - & - & - \\
\hline \multirow[t]{2}{*}{ Breast Feeding (6 months) } & No & - & - & - & 1,810 & $246(13.6)$ & 0.008 & - & - & - \\
\hline & Yes & - & - & - & 1,264 & $216(17.1)$ & & - & - & - \\
\hline \multirow[t]{2}{*}{ Antibiotics (first 1 year) } & No & - & - & - & 1,936 & 225 (11.6) & $<0.001$ & - & - & - \\
\hline & Yes & - & - & - & 1,138 & $237(20.8)$ & & - & - & - \\
\hline \multirow[t]{2}{*}{ Paracetamol (first 1 year) } & No & - & - & - & 1,099 & $138(29.9)$ & 0.004 & - & - & - \\
\hline & Yes & - & - & - & 1975 & $324(70.1)$ & & - & - & - \\
\hline \multirow[t]{2}{*}{ LRTI (first 1 year) } & No & - & - & - & 2,383 & $286(12 \%)$ & $<0.001$ & - & - & - \\
\hline & Yes & - & - & - & 691 & $176(25.5 \%)$ & & - & - & - \\
\hline \multirow[t]{2}{*}{ Farm animal } & No & - & - & - & 2,962 & $435(14.7 \%)$ & 0.006 & - & - & - \\
\hline & Yes & - & - & - & 112 & $27(24.1)$ & & - & - & - \\
\hline \multirow[t]{2}{*}{ Paracetamol } & No & 893 & $99(11.1)$ & $<0.001$ & 415 & $40(9.6)$ & 0.001 & 478 & $59(12.3)$ & 0.001 \\
\hline & Yes & 5,398 & $925(17.1)$ & & 2,659 & $422(15.9)$ & & 2,739 & $503(18.4)$ & \\
\hline Exercise & No & 4,032 & $558(13.8)$ & $<0.001$ & 2,264 & 308 (13.) & $<0.001$ & 1,768 & $250(14.1)$ & $<0.001$ \\
\hline & Yes & 2,259 & $466(20.6)$ & & 810 & $154(19.0)$ & & 1,449 & $312(21.5)$ & \\
\hline Parent Smoke & No & 6,025 & $982(16.3)$ & 0.826 & 2,927 & $438(15.0)$ & 0.652 & 3,098 & $544(17.6)$ & 0.493 \\
\hline & Yes & 266 & $42(15.8)$ & & 147 & $24(16.3)$ & & 119 & $18(15.1)$ & \\
\hline Pet & & & & & & & & & & \\
\hline Dog Now & No & 4,275 & $728(15.0)$ & 0.030 & 2,477 & $366(15.0)$ & 0.978 & 2,248 & $362(16.5)$ & 0.020 \\
\hline & Yes & 1,566 & $283(18.1)$ & & 597 & $90(15.1)$ & & 969 & $193(19.9)$ & \\
\hline Cat Now & No & 5,317 & $813(15.5)$ & $<0.001$ & 2,759 & $403(14.8)$ & 0.271 & 2,558 & $410(16.3)$ & 0.001 \\
\hline & Yes & 974 & $197(20.2)$ & & 315 & $54(17.1)$ & & 659 & $143(21.7)$ & \\
\hline Truck Traffic & & & & $<0.001$ & & & $<0.001$ & & & $<0.001$ \\
\hline Never & & 3,410 & 459 (13.5) & & 1,988 & $251(12.6)$ & & 1,422 & $208(14.6)$ & \\
\hline Sometime & & 2,114 & $384(18.2)$ & & 751 & $131(17.4)$ & & 1,363 & $253(18.6)$ & \\
\hline Always & & 767 & $181(23.6)$ & & 335 & $80(23.9)$ & & 432 & $101(23.4)$ & \\
\hline Fire Cooking & No & 6,036 & $979(16.2)$ & 0.545 & 2,928 & $442(15.1)$ & 0.645 & 3,108 & $537(17.3)$ & 0.126 \\
\hline & Yes & 255 & $45(17.6)$ & & 146 & $20(13.7)$ & & 109 & $25(22.9)$ & \\
\hline Env Factors & & & & & & & & & & \\
\hline Cockroach & No & 4,273 & $664(15.5)$ & 0.021 & 1,973 & $281(14.2)$ & 0.102 & 2,300 & $383(16.7)$ & 0.053 \\
\hline & Yes & 2,018 & $360(17.8)$ & & 1,101 & $181(16.4)$ & & 917 & $179(19.5)$ & \\
\hline Air Conditioner & No & 3,993 & $619(15.5)$ & 0.028 & 1,820 & $259(14.2)$ & 0.136 & 2,173 & $360(16.6)$ & 0.052 \\
\hline & Yes & 2,298 & $405(17.6)$ & & 1,254 & $203(16.2)$ & & 1,044 & $202(19.3)$ & \\
\hline Tree or Flower & No & 2,238 & $343(15.3)$ & 0.129 & 796 & $106(13.3)$ & 0.116 & 1,442 & $237(16.4)$ & 0.164 \\
\hline & Yes & 4,053 & $681(16.8)$ & & 2,278 & $356(15.6)$ & & 1,775 & $325(18.3)$ & \\
\hline Perfume & No & 3,591 & $557(15.5)$ & 0.058 & 1,536 & $199(13.0)$ & 0.001 & 2,055 & $358(17.4)$ & 0.923 \\
\hline & Yes & 2,700 & $467(17.3)$ & & 1,538 & $263(17.1)$ & & 1,162 & $204(17.6)$ & \\
\hline School Type & & & & 0.575 & & & 0.763 & & & 0.207 \\
\hline Public & & 4,170 & $671(16.1)$ & & 1,957 & $125(10.5)$ & & 1,370 & $226(16.5)$ & \\
\hline Private & & 2,121 & $353(16.6)$ & & 1,117 & $165(14.8)$ & & 1,004 & $188(18.7)$ & \\
\hline
\end{tabular}


苛

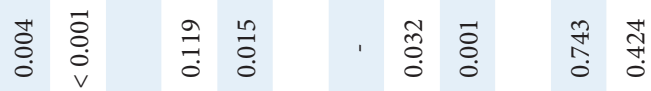

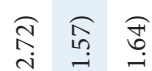

开

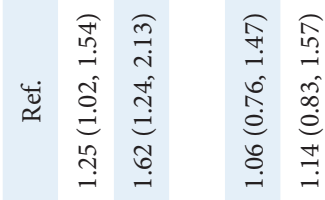

总

훙

䓪

곡

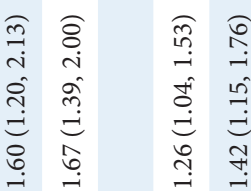

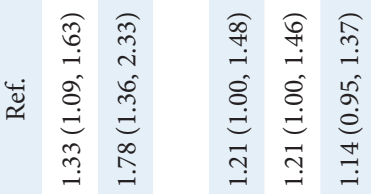

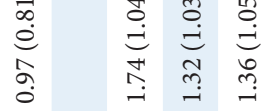

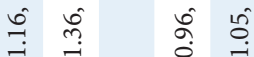

的莎气

$\begin{array}{ll} & \overrightarrow{8} \\ 0 & 0 \\ 0 & 0 \\ 0\end{array}$

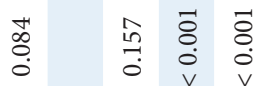

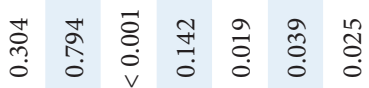

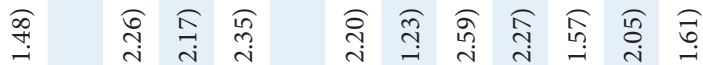

की की की की की की

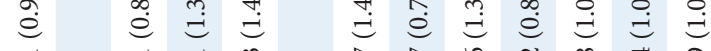

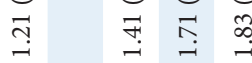

בิ

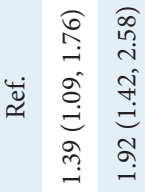

雚

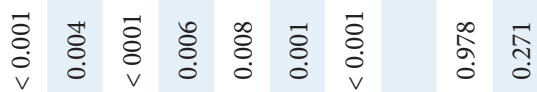

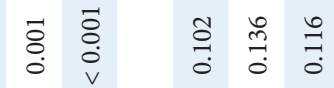

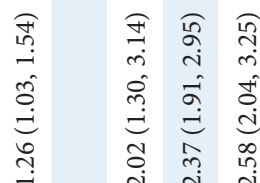

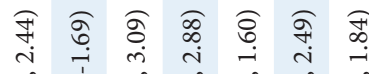

ণ্ড়

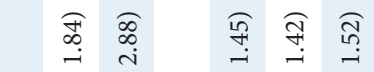

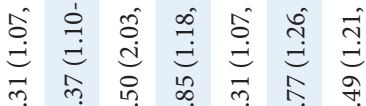

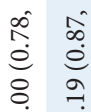

$\ddot{\leftrightarrow}$

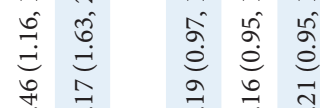
\%

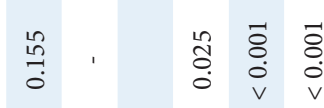

$\begin{array}{llll}\overrightarrow{0} & \overrightarrow{0} & \infty & \infty \\ 0 & 0 & 0 \\ 0 & 0 & 0 \\ 0 & 0 & 0\end{array}$

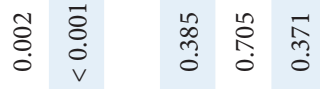

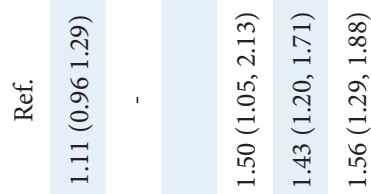

总

옥

氙

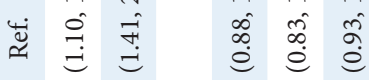

苛 尊

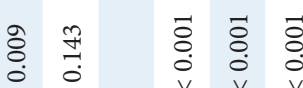

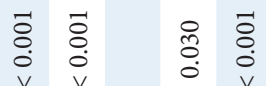

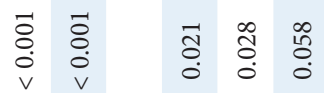

हิ?

商

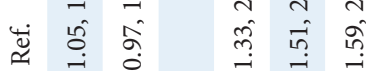

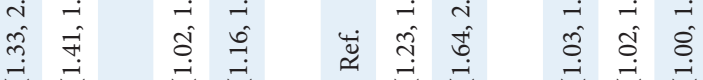

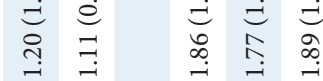

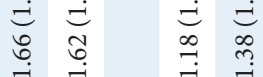

भ

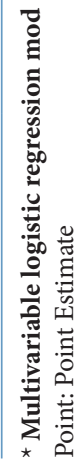


Concerning the age group of 6-7 years, parental history of $\mathrm{AR}$ and eczema was significantly related to current AR (AR: $\mathrm{p}<0.001, \mathrm{OR}=1.71,95 \% \mathrm{CI}=1.35-2.17$; eczema: $\mathrm{p}<0.001$, $\mathrm{OR}=1.83,95 \% \mathrm{CI}=1.42-2.35)$. Lower respiratory tract infection (LRTI) in the first year of life was positively associated with current AR ( $\mathrm{p}<0.001, \mathrm{OR}=1.86,95 \% \mathrm{CI}=1.34-2.59$ ). Parental reported breastfeeding (six months) was positively associated with current $\mathrm{AR}(\mathrm{p}=0.019, \mathrm{OR}=1.28,95 \% \mathrm{CI}=$ 1.04-1.57). The frequency of truck traffic on the street of residence was positively associated with the prevalence of current $A R$ for both the occasional truck traffic group $(\mathrm{p}=0.007$, $\mathrm{OR}=1.39,95 \% \mathrm{CI}=1.09-1.76)$ and the always truck traffic group $(\mathrm{p}<0.001, \mathrm{OR}=1.92,95 \% \mathrm{CI}=1.42-2.58)$, as shown in Tables 2 and 3.

In the children aged 13-14 years, parental history of atopy was not significantly related to an increased risk of current AR. Current use of paracetamol, however, was associated with increased risk of current $\mathrm{AR}$ ( $\mathrm{p}=0.004, \mathrm{OR}=1.57,95 \% \mathrm{CI}=$ 1.16-2.14). Only current cat exposure was associated with increased risk of current $\mathrm{AR}$ ( $\mathrm{p}=0.015, \mathrm{OR}=1.32,95 \% \mathrm{CI}=$ 1.05-1.64). The frequency of truck traffic on the street of residence was also positively associated with the prevalence of current $\mathrm{AR}$ in both the occasional truck traffic group ( $\mathrm{p}=$ $0.032, \mathrm{OR}=1.25,95 \% \mathrm{CI}=1.02-1.54)$ and the always truck traffic group $(\mathrm{p}<0.001, \mathrm{OR}=1.62,95 \% \mathrm{CI}=1.24-2.13)$, as shown in Tables 2 and 3.

\section{Discussion}

The results from our study showed the prevalence of current $\mathrm{AR}$ in the children aged 6-7 years to be $15.0 \%$. When compared to ISAAC phase III in the Bangkok area at $13.4 \%$, there was a slightly but significantly increased prevalence in the younger age group $(\mathrm{p}=0.006)$. In this study, the prevalence of current AR in the 13-14-year age group was $17.5 \%$. This decrease was significant when compared to ISAAC phase III in Bangkok (23.9\%, $\mathrm{p}=0.006)$. The mean global prevalence of current AR in both age groups was $9.1 \%$ and $16 \%$, respectively, in which the Asia-Pacific prevalence was $5.8 \%$ and the ISAAC phase III prevalence was $14.5 \%$. The results of our study so far show a higher percentage in both prevalences.

Our study confirms that parental atopy is a risk factor for the development of AR. These results are consistent with the findings of other studies. ${ }^{15,16}$ Both genetic and environmental factors play important roles in the etiology of AR. It is likely that there is a multilevel interaction between genetic and environmental factors. ${ }^{17}$

This study did not find any association between antibiotic use in the first year of life and later AR. We found a positive relation between current consumption of paracetamol and the prevalence of current AR. There is a dose-related association between acetaminophen use and AR in children. ${ }^{18}$ The association of paracetamol with allergic disease is possible due to the depletion of glutathione. This is a result of the pharmacokinetics of this drug, leaving the respiratory mucosa with inadequate antioxidant protection. ${ }^{19}$ This mechanism could explain the possible association between paracetamol consumption and the prevalence of the symptoms of rhinitis in our patients.
Our results show that LRTI in the first year of life was positively associated with current AR. Respiratory infections are among the major causes of hospitalization and pediatric medical consultation, and they are directly associated with mortality in children. ${ }^{20}$ Allergic children showed a significantly higher number of respiratory infections in comparison with the non-allergic group. ${ }^{21}$ Epidemiological studies have investigated significant relationships between AR and LRTI. ${ }^{22}$

In phase III of ISAAC, there was no consistent association between breastfeeding in the first year of life and rhinoconjunctivitis in 6-7-year-old children. However, breastfeeding was associated with reduced prevalence of current symptoms of severe rhinoconjunctivitis. ${ }^{23}$ Our results suggest that breastfeeding (six months) was associated with current AR. Several studies have shown that breastfeeding in developing countries is associated with protection against infections, particularly gastric infection and diarrhea. ${ }^{24}$ The immunological properties of breast milk are significant contributing factors to infant health in poor countries. Breastfeeding is therefore rightly promoted by authorities such as the World Health Organization. $^{25}$

ISAAC phase III showed that early-life exposure to cats is a risk factor for symptoms of rhinoconjunctivitis in 6-7-yearold children. Current exposure to cats and dogs combined, and only to dogs, is a risk factor for symptom reporting by 13-14-year-old adolescents worldwide. ${ }^{26}$ The Melbourne Atopy Cohort study (MASC) showed no evidence that exposure to cats and dogs at birth increases the risk of allergic disease in high-risk children. ${ }^{27}$ The Childhood Origins of ASThma (COAST) showed associations between allergen-specific sensitization and rhinitis. At one year, sensitization to cats was the only aeroallergen associated with an increased risk of rhinitis at 6 years of age. At age 6 years, sensitization to all allergens tested except cockroach was associated with concurrent rhinitis. ${ }^{28}$

In this study, we found a positive global relationship between childhood symptoms of current AR and self-reported frequency of truck traffic on the street of residence. The associations were remarkably similar in different parts of the world in the two age groups studied and when using a selfcompleted questionnaire and a parent-completed questionnaire for 6-7-year-old children. ${ }^{29}$ A recent study from Italy found that self-reported traffic density in the area of residence was clearly associated with nitrogen dioxide, which was 39 $\mu \mathrm{g} / \mathrm{m}^{3}$ when self-reported traffic was "absent," $44 \mu \mathrm{g} / \mathrm{m}^{3}$ when "low," $48 \mu \mathrm{g} / \mathrm{m}^{3}$ when "intermediate," and $52 \mu \mathrm{g} / \mathrm{m}^{3}$ when "high." ${ }^{30}$ First, there are now several published studies that have used objective measures of exposure and effect and found similar relationships between truck traffic exposure or other measures of exposure to vehicular traffic and respiratory and allergic symptoms in children. ${ }^{31,32}$ Second, these studies were conducted mostly in Western Europe and North America, and in ISAAC phase III the associations found in these regions were not different from those found in other parts of the world. One could argue that concern about possible adverse effects on respiratory health by traffic fumes is different in different parts of the world, so one would not expect to see a universal association if responder bias played much of a role. Third, the associations were similar for the 
13-14-year-olds and the 6-7-year-olds, despite the fact that the teenagers completed the questionnaires themselves, whereas the parents completed the questionnaires for the 6-7-year-olds. We can only speculate about what factors influence the remaining heterogeneity of exposure-response relationships between participating centers. There is experimental evidence to support that diesel particles may enhance allergic sensitization to common inhalant allergens..$^{33}$

The major strengths of our study included standardized written core questionnaires (GAN 2016) for AR modified from ISAAC questionnaires, a well-established and standardized protocol, and a high response rate. One limitation of our study is that it is cross-sectional, which limits our ability to determine causation. Another limitation is that symptoms of AR were self-reported in the questionnaire; therefore, we could not confirm with physical examination and laboratory investigations.

In conclusion, our study shows that the prevalence of $A R$ remained high in both age groups. Our data confirm that a family history of atopy, LRTI in the first year of life, breastfeeding (six months), current paracetamol use, exercise, current cat exposure, and truck traffic on the street of residence are important and significant risk factors for AR symptoms. This study may serve as evidence-based health education for parents to reduce the prevalence of $\mathrm{AR}$ by proper management of common disease (current use of paracetamol, LRTI in the first year of life, asthma, eczema) and environmental control (pets and truck traffic on the street of residence). More detailed studies are needed on the risk factors of AR.

\section{Acknowledgements}

The study was completed with significant contributions from the colleagues of the allergy centers, Bhumibol Adulyadej Hospital. The authors wish to thank:

Mr Sutthisak Srisawad

Mr Itti Chinratanapisit

Ms Chanutr Chinratanapisit

The authors would like to thank all the children, parents, and teachers who participated in this study. We also thank those who helped with the field work.

This study was co-supported by grants from the National Research Council of Thailand; the Allergy, Asthma, and Immunology Association of Thailand; the Royal College of Pediatricians of Thailand; and the Pediatric Society of Thailand.

\section{References}

1. Wallace DV, Dykewicz MS, Bernstein DI, Blessing-Moore J, Cox L, Khan DA, et al. The diagnosis and management of rhinitis: an updated practice parameter. J Allergy Clin Immunol.2008;122(2 Suppl):S1-84.

2. Ng ML, Warlow RS, Chrishanthan N, Ellis C, Walls RS. Preliminary criteria for the definition of allergic rhinitis: a systematic evaluation of clinical parameters in a disease cohort (II). Clin Exp Allergy. 2000;30:1417-22.

3. Vandenplas O, Vinnikov D, Blanc PD, Agache I, Bachert C, Bewick M, et al. Impact of rhinitis on work productivity: a systematic review. J Allergy Clin Immunol Pract. 2018;6:1274-1286.e9.

4. Schatz M, Zeiger RS, Chen W, Yang SJ, Corrao MA, Quinn VP. The burden of rhinitis in a managed care organization. Ann Allergy Asthma Immunol. 2008;101:240-7.
5. Strachan D, Sibbald B, Weiland S, Ait-Khaled N, Anabwani G, Anderson $\mathrm{HR}$, et al. Worldwide variations in prevalence of symptoms of allergic rhinoconjunctivitis in children: the International Study of Asthma and Allergies in Childhood (ISAAC). PediatrAllergy Immunol.1997;8:161-76.

6. Bjorksten B, Clayton T, Ellwodd P, Strachan D. Worldwide time trends for symptoms of rhinitis and conjunctivitis: phase III of the International Study of Asthma and Allergies in Childhood. Pediatr Allergy Immunol. 2008;19:110-24

7. Vichyanond P, Jirapongsananuruk O, Visitsuntorn N, Tuchinda M. Prevalence of asthma, rhinitis and eczema in children from the Bangkok area using the ISAAC (International Study for Asthma and Allergy in Children) questionnaires. J Med Assoc Thai. 1998;81:175-84.

8. Trakultivakorn M, Sangsupawanich P, Vichyanond P. Time trends of the prevalence of asthma, rhinitis and eczema in Thai children-ISAAC (International Study of Asthma and Allergies in Childhood) Phase Three. J Asthma. 2007;44:609-11.

9. ISAAC [Internet]. Auckland: the ISAAC Steering Committee; 2018. ISAAC Phase Three [cited 2018 May 24]; [about 1 screen]. Available from: http:// isaac.auckland.ac.nz/ phases/phasethree/phasethree.html

10. Ng ML, Warlow RS, Chrishanthan N, Ellis C, Walls RS. Preliminary criteria for the definition of allergic rhinitis: a systematic evaluation of clinical parameters in a disease cohort (II). Clin Exp Allergy. 2000;30: 1417-22.

11. Asher MI, Keil U, Anderson HR, Beasley R, Crane J, Martinez F, et al. International Study of Asthma and Allergies in Childhood (ISAAC): rationale and methods. Eur Respir J. 1995;8:483-91.

12. Ellwood P, Asher MI, Beasley R, Clayton TO, Stewart AW. The international study of asthma and allergies in childhood (ISAAC): phase three rationale and methods. Int J Tuberc Lung Dis. 2005;9:10-6.

13. Ellwood P, Asher I, Ellwood E. Globalasthmanetwork.org [Internet]. Auckland: Global Asthma Network. The Global Asthma Network Manual for Global Surveillance [updated 2016 Feb 22; cited 22 May 2018]; [about 1 screen]. Available from: http://www.globalasthmanetwork.org/surveillance/ manual/manual.php

14. ISAAC Steering Committee; International Study of Asthma and Allergies in Childhood. 2nd ed. Auckland; ISAAC Phase One Manual; 1993.

15. Tamay Z, Akcay A, Ones U, Guler N, Kilic G, Zencir M. Prevalence and risk factors for allergic rhinitis in primary school children. Int J PediatrOtorhinolaryngol.2007;71:463-71.

16. Aberg N. Familial occurrence of atopic disease: genetic versus environmental factors. Clin Exp Allergy. 1993;23:829-34.

17. Kauffmann F, Dizier MH, Annesi-Maesano I, Bousquet J, Charpin D, Demenais $\mathrm{F}$, et al. EGEA (epidemiological study on the genetics and environment of asthma, bronchial hyperresponsiveness and atopy) -descriptive characteristics. Clin Exp Allergy. 1999;29:17-21.

18. Davey G, Berhane Y, Duncan P, Aref-Adib G, Britton J, Venn A. Use of acetaminophen and the risk of self-reported allergic symptoms and skin sensitization in Butajira, Ethiopia. J Allergy Clin Immunol. 2005;116:863-8.

19. Camargo C Jr, Barr RG. Acetaminophen and the risk of asthma: the epidemiologic and pathophysiologic evidence. Chest. 2005;127:604-12.

20. Hernandez-Trujillo VP. Approach to Children with Recurrent Infections. Immunol Allergy Clin North Am. 2015;35:625-36.

21. Ciprandi G, Tosca MA, Fasce L. Allergic children have more numerous and severe respiratory infections than non-allergic children. Pediatr Allergy Immunol. 2006;17:389-91.

22. de Oliveira TB, Klering EA, da Veiga ABG. Is recurrent respiratory infection associated with allergic respiratory disease? J Asthma. 2019;56: $160-6$.

23. Bjorksten B, Ait-Khaled N, Innes Asher M, Clayton TO, Robertson C, and the ISAAC Phase Three Study Group. Global analysis of breast feeding and risk of symptoms of asthma, rhinoconjunctivitis and eczema in 6-7 year old children: ISAAC Phase Three. Allergol Immunopathol. 2011;39:318-25.

24. Hanson LA, Korotkova M, Haversen L, Mattsby-Baltzer I, Hahn-Zoric M, Silfverdal SA, et al. Breast-feeding, a complex support system for the offspring. Pediatr Int. 2002;44:347-52.

25. World Health Organization U. Global strategy for infant and young child feeding. Geneva; 2003. Report No.: 9241562218.

26. Brunekreef B, Von Mutius E, Wong G, Odhiambo J, Garcia-Marcos L, Foliaki S. Exposure to cats and dogs, and symptoms of asthma, rhinoconjunctivitis, and eczema. Epidemiology. 2012;23:742-50.

27. Lodge CJ, Lowe AJ, Gurrin LC, Matheson MC, Balloch A, Axelrad C, et al. Pets at birth do not increase allergic disease in at-risk children. Clin Exp Allergy. 2012;42:1377-85. 
28. Stoltz DJ, Jackson DJ, Evans MD, Gangnon RE, Tisler CJ, Gern JE, et al. Specific patterns of allergic sensitization in early childhood and asthma \& rhinitis risk. Clin Exp Allergy. 2013;43:233-41.

29. Brunekreef B, Stewart AW, Anderson HR, Lai CK, Strachan DP, Pearce N. Self-reported truck traffic on the street of residence and symptoms of asthma and allergic disease: a global relationship in ISAAC phase 3. Environ Health Perspect. 2009;117:1791-8.

30. Cesaroni G, Badaloni C, Porta D, Forastiere F, Perucci CA. Comparison between various indices of exposure to traffic-related air pollution and their impact on respiratory health in adults. Occup Environ Med. 2008;65: $683-90$
31. Annesi-Maesano I, Moreau D, Caillaud D, Lavaud F, Le Moullec Y, Taytard A, et al. Residential proximity fine particles related to allergic sensitisation and asthma in primary school children. Respir Med. 2007;101:1721-9.

32. Bayer-Oglesby L, Schindler C, Hazenkamp-von Arx ME, Braun -Fahrlander C, Keidel D, Rapp R, et al. Living near main streets and respiratory symptoms in adults: the Swiss Cohort Study on Air Pollution and Lung Diseases in Adults. Am J Epidemiol. 2006;164:1190-8.

33. Brunekreef B, Holgate ST. Air pollution and health. Lancet. 2002; $3601233-42$. 


\title{
A novel allergen-specific therapy with regulatory $T$ cells induced by CD40-silenced dendritic cells
}

\author{
Motohiko Suzuki, Makoto Yokota, Shinya Ozaki, Yoshihisa Nakamura
}

\begin{abstract}
Background: We previously reported that dendritic cells (DCs) transfected with CD40 siRNA and pulsed by ovalbumin (OVA) (CD40-silenced OVA DCs) inhibited allergic responses through facilitation of regulatory T cells (Tregs). However, to our knowledge, no prior study has examined allergen-specific therapy by administration of siRNA-induced Tregs for the control of allergy.
\end{abstract}

Objective: We aimed to investigate the effect of Tregs induced in vitro on allergic responses and symptoms in vivo.

Methods: Mice were treated with Tregs (OVA DCs-induced Tregs) induced by CD40-silenced OVA DCs or Tregs (nonantigen DCs-induced Tregs) induced by DCs transfected with CD40 siRNA and pulsed with no antigen, and the effects of these Tregs on allergic responses were estimated.

Results: Administration of nonantigen DCs-induced Tregs prevented not only OVA-induced allergy but also keyhole limpet hemocyanin-induced allergy. Administration of OVA DCs-induced Tregs significantly reduced the number of sneezes and nasal rubbing movements, eosinophilia in the nasal mucosa, and the level of OVA-specific IgE in mice with OVA-induced allergy, compared with CD40-silenced nonantigen DC-induced Tregs in numbers 20 times greater, even in mice with established allergic rhinitis. Furthermore, Tregs induced by CD40-silneced DCs pulsed with Cry j 1, a major allergen of Japanese cedar pollen, inhibited Japanese cedar-induced allergy.

Conclusions: This study shows for the first time that both antigen-independent Tregs and antigen-specific Tregs can be induced by siRNA, and that therapy with siRNA-induced Tregs inhibits allergic responses and symptoms. It also shows that antigen-specific Tregs have more potent effects in inhibiting allergic responses than antigen-nonspecific Tregs.

Key words: Regulatory T cells, Allergy, CD40, siRNA, Dendritic cells.

\section{From:}

Departments of Otorhinolaryngology, Nagoya City University
Corresponding author:

Motohiko Suzuki

Departments of Otorhinolaryngology, Nagoya City University

1 Kawasumi, Mizuho-cho, Mizuho-ku, Nagoya, 467-8601, Japan

E-mail: suzu-mo@med.nagoya-cu.ac.jp

\section{Introduction}

CD40 is an integral membrane protein in dendritic cells (DCs) that activates T cells. Blockade of the CD40-CD40L interaction is a potent tolerance-inducing strategy, ${ }^{1,2}$ while the inhibition of this interaction suppresses $\mathrm{T}$ cell responses ${ }^{3}$ and generates regulatory $\mathrm{T}$ cells (Tregs). ${ }^{4}$

RNA interference using small interfering RNA (siRNA) induces specific silencing of gene expression, and is a potent, selective, and easy method. ${ }^{5}$ Andrew Fire and Craig Mello received the Nobel Prize in Medicine for this discovery. Silencing gene expression by siRNA is more useful and promising than conventional silencing strategies by gene or antibody, such as blocking antibody, blocking protein, antisense oligonucleotide, and ribozymes. ${ }^{6-8}$

We previously reported that vector expressing siRNA specific for CD40 (CD40 siRNA) inhibits allergic responses not only as a means of prevention ${ }^{9}$ but also as treatment. ${ }^{10}$ However, direct administration of vector expressing siRNA may induce complications, because it is an antigen-nonspecific therapy and the vector or siRNA may change immune responses in vivo. We also showed that administration of CD40-silenced antigen-specific dendritic cells (DCs), transfected with CD40 siRNA but not vector CD40 siRNA and pulsed by antigen in vitro, 
inhibited allergic responses and symptoms antigen-specifically. ${ }^{11}$ However, CD40-silenced antigen-specific DCs may lead to unexpected complications in vivo, since siRNA in CD40-silenced DCs may cause unexpected problems. We additionally documented that CD40-silenced DCs induce facilitation of $\mathrm{CD} 4{ }^{+} \mathrm{CD} 25^{+}$Tregs in vivo. ${ }^{11}$ Furthermore, induction of Tregs by CD40-silenced DCs is not always the same by the conditions in vivo. Considering this, direct administration of antigen -specific $\mathrm{CD}^{+}{ }^{+} \mathrm{CD} 25^{+}$Tregs, induced by siRNA in vitro, is an attractive strategy for safer and more effective control of allergic diseases. To our knowledge, however, therapy with antigen -specific $\mathrm{CD} 4^{+} \mathrm{CD} 25^{+}$Tregs induced by siRNA in vitro has not been reported for the control of allergy, and its usefulness is not known.

The generation of Tregs with anti-CD3/CD28 antibodies in vitro has been reported. ${ }^{12}$ However, these are not antigenspecific Tregs. Antigen-specific Tregs are attractive for the treatment of allergy, since antigen-nonspecific Tregs may affect various immune responses and contribute to a range of diseases, including cancer. ${ }^{13}$ It has been also reported that inducedTregs generated by anti-CD3/CD28 antibodies differ from those induced by physiological-like activation with antigen/ APC..$^{14}$

In this study, we examined the effect on allergic diseases of $\mathrm{CD} 4^{+} \mathrm{CD} 25^{+}$Tregs induced by antigen-specific DCs transfected with siRNA in vitro. The results showed that administration of ovalbumin (OVA)-specific $\mathrm{CD} 4{ }^{+} \mathrm{CD} 25^{+}$Tregs, induced by DCs transfected with CD40 siRNA and pulsed with OVA in vitro, inhibited allergic responses and symptoms in mice with allergic rhinitis, and that CD40-silenced DCs pulsed without antigen induced antigen-nonspecific Tregs. It was also shown that antigen-specific Tregs were more potent in inhibiting allergic responses and symptoms than antigen-nonspecific Tregs.

\section{Methods \\ Generation of bone marrow-derived DCs and gene silencing by SiRNA}

DCs were generated from bone marrow progenitor cells, as previously described., ${ }^{9,10,11}$ These DCs were transfected with transfection reagent alone (No siRNA DCs), siRNA (Control siRNA) specific to the Luciferase gene GL2 Duplex siRNA (Control DCs), or siRNA (CD40 siRNA, UUCUCAGCCCAG UGGAACA) specific to CD40. DCs transfected with CD40 siRNA were pulsed with OVA (CD40-silenced OVA DCs) or without OVA (CD40-silenced nonantigen DCs), as described previously. ${ }^{9,10,11}$ DCs transfected with CD40 siRNA were also pulsed with Cry j 1, a major allergen of Japanese cedar (Cryptomeria japonica) pollen, (CD40-silenced Cry j 1 DCs) by the same method. Cry j 1 was purified by the method previously reported. ${ }^{15,16}$

\section{Generation of Tregs in vitro}

Mouse naïve CD4 ${ }^{+} \mathrm{T}$ cells were isolated from splenic cells of six to eight week-old male BALB/c mice using a Mouse Naïve $\mathrm{CD}^{+} \mathrm{T}$ Cell Isolation Kit (R\&D Systems, CA). Mouse naïve $\mathrm{CD}^{+} \mathrm{T}$ cells $\left(3 \times 10^{5} / \mathrm{mL}\right)$ were co-cultured with $6 \times 10^{5} / \mathrm{mL}$ No siRNA DCs, Control DCs, CD40-silenced nonantigen DCs, CD40-silenced OVA DCs, or CD40-silenced Cry j 1 DCs for 5 days in $2 \mathrm{~mL}$ of complete medium, RPMI 1640 supplemented with $2 \mathrm{mM}$ L-glutamine, $100 \mathrm{U} / \mathrm{mL}$ penicillin, $100 \mu \mathrm{g} / \mathrm{mL}$ streptomycin, $50 \mu \mathrm{M} 2-\mathrm{ME}$, and 10\% FCS supplemented with TGF- $ß(5 \mathrm{ng} / \mathrm{mL})$ and IL-2 $(50 \mathrm{IU} / \mathrm{mL}) . \mathrm{CD}^{+} \mathrm{CD} 25^{+} \mathrm{T}$ cells were collected using a MACS negative CD4 isolation kit and anti-CD25 MACS beads (Miltenyi Biotec, Bergisch Gladbach, Germany). ${ }^{9}$

\section{Immunization and Treatment}

Six to eight week-old male BALB/c mice (Japan SLC Inc., Shizuoka, Japan) were injected intravenously with PBS alone, Tregs $\left(4 \times 10^{5}, 4 \times 10^{6}\right.$, or $8 \times 10^{6}$ cells/mouse $)$ induced by CD40-silenced nonantigen DCs, or Tregs $\left(4 \times 10^{5}\right.$ cells/mouse $)$ induced by CD40-silenced OVA DCs on day 1 . Mice were also injected intraperitoneally (i.p.) with $4 \mathrm{mg} \mathrm{Al}(\mathrm{OH})_{3}$ and $10 \mu \mathrm{g}$ ovalbumin (OVA) twice on days 2 and 15. Each group consisted of five mice. The same mice were challenged intranasally (i.n.) on days 21 through 27 with OVA $(100 \mu \mathrm{g})$. Samples were collected on day 28.

In the second experiment, the protocol was the same as in the above experiment except that mice received PBS alone, Tregs $\left(4 \times 10^{5}\right.$ or $4 \times 10^{6}$ cells/mouse) induced by CD 40 -silenced nonantigen DCs, or Tregs $\left(4 \times 10^{5}\right.$ or $4 \times 10^{6}$ cells/mouse $)$ induced by CD40-silenced OVA DCs and that mice were injected i.p. with $4 \mathrm{mg} \mathrm{Al}(\mathrm{OH})_{3}$ and keyhole limpet hemocyanin $(\mathrm{KLH})$, but not OVA, on days 2 and 15 and challenged i.n. on days 21 through 27 with KLH.

In the third experiment, mice were sensitized with OVA $(10 \mu \mathrm{g})$ and $2 \mathrm{mg} \mathrm{Al}(\mathrm{OH})_{3}$ intraperitoneally on days 1 and 14 , and then the same mice were challenged intranasally with OVA $(100 \mu \mathrm{g})$ on days 18 through 24 . Intravenous administration of PBS alone, Tregs induced by CD40-silenced nonantigen DCs $\left(4 \times 10^{6}\right.$ or $8 \times 10^{6}$ cells/mouse), or Tregs by CD40-silenced OVA DCs $\left(4 \times 10^{5}\right.$ cells/mouse $)$, was performed on day 26. These mice were then re-challenged intranasally on days 27 through 32 with OVA $(100 \mu \mathrm{g})$.

In the fourth experiment, mice were sensitized with Cry j $1(3 \mu \mathrm{g})$ and $2 \mathrm{mg} \mathrm{Al}(\mathrm{OH})_{3}$ intraperitoneally on days 1 and 14 , and then the same mice were challenged intranasally with Cry j 1 ( $2 \mu \mathrm{g})$ on days 18 through 24 . Intravenous administration of PBS alone, Tregs induced by CD40-silenced nonantigen DCs $\left(8 \times 10^{6}\right.$ cells/mouse), or Tregs by CD40-silenced Cry j 1 DCs $\left(4 \times 10^{5}\right.$ cells/mouse), was performed on day 26 . These mice were then re-challenged intranasally on days 27 through 32 with Cryj 1 ( $3 \mu \mathrm{g})$.

This study was approved by Research Ethics Committee in Nagoya City University. Mice were housed in an environmentally-controlled animal facility at Nagoya City University in Japan. The protocols were in accordance with the Guidelines for Care and Use of Animals of Nagoya City University. Every effort was made to minimize the discomfort of the animals.

\section{Cry j 1-specific $T$ cell response}

$\mathrm{CD} 4^{+} \mathrm{CD} 25^{-} \mathrm{T}$ cells and CD11c cells were isolated from spleen using MACS beads (Miltenyi Biotech). Spleen CD4 ${ }^{+}$ CD25- T cell $\left(2 \times 10^{6}\right.$ cells $\left./ \mathrm{mL}\right)$ and DC $\left(2 \times 10^{5}\right.$ cells $\left./ \mathrm{mL}\right)$ suspensions were cultured for $72 \mathrm{~h}$ and stimulated with $10 \mu \mathrm{g} / \mathrm{mL}$ Cry j 1 antigen. 


\section{OVA- specific T cell response}

Splenic cells isolated by gradient centrifugation over Ficoll -Paque (Amersham Pharmacia Biotech, Uppsala, Sweden) were cultured in 96-well plates at a concentration of $4 \times 10^{5}$ cells/well for $72 \mathrm{~h}$ in the presence of $100 \mu \mathrm{g} / \mathrm{mL}$ OVA antigen.

\section{Measurement of IL-2 production}

Spleen $\mathrm{CD} 4^{+} \mathrm{CD} 25^{-} \mathrm{T}$ cell $\left(2 \times 10^{6}\right.$ cells $\left./ \mathrm{mL}\right)$ and $\mathrm{DC}(2 \times$ $10^{5}$ cells $/ \mathrm{mL}$ ) transfected with or without CD40 siRNA suspensions were cultured for 72 hours, stimulated with $10 \mu \mathrm{g} / \mathrm{mL}$ Cry j 1. Quantities of IL-2 cytokines in the culture supernatants were determined by using a sandwich ELISA. Plates were coated with anti-mouse IL-2 (BioLegend, San Diego, CA). The culture supernatant was then added, and the plates were incubated with the second antibody of biotinylated anti-mouse IL-2 (BioLegend). Standard curves were generated by using recombinant cytokines.

\section{Measurement of OVA-specific, KLH-specific, and Cry j 1-spe- cific IgE in sera}

Titers of specific IgE were measured by ELISA. Briefly, ELISA plates were coated with anti-mouse IgE monoclonal antibody (Yamasa, Tokyo, Japan). Non-specific binding was blocked and sera were added. After washing with wash buffer, biotinylated OVA, KLH, or Cry $\mathrm{j} 1$ was added to the well. The plates were then incubated with avidin-peroxidase at $37^{\circ} \mathrm{C}$ for an hour after washing. The TMB microwell peroxidase substrate system (KPL, Gaithersburg, MD) was used, and optical density (O.D.) was measured at $450 \mathrm{~nm}$.

\section{Nasal allergic symptoms}

Immediately after the last nasal challenge, the number of sneezes and nasal rubbing movements was counted for $20 \mathrm{~min}$ according to the method previously reported. ${ }^{11}$

\section{Pathology}

The heads were decalcified and sectioned. Three micrometer thick sections of nasal tissue were stained with Luna staining. The number of eosinophils in the nasal mucosa of the nasal septum was counted microscopically in a field of view at $400 \times$ magnification. The observer was blinded to treatment when counting the number of eosinophils.

\section{Statistical analysis}

Data are expressed as means \pm SEM. Statistical comparisons between groups were performed using one-way ANOVA followed by the Newman-Keuls Test. Differences with $P$-values less than 0.05 were considered significant.

\section{Results \\ Prevention of OVA-induced allergy with CD40-silenced DC-induced OVA Tregs}

We investigated whether Tregs induced by CD40-silenced OVA DCs in vitro could prevent OVA-induced allergy. Mice that received PBS, CD40-silenced nonantigen DC-induced $\mathrm{CD} 4{ }^{+} \mathrm{CD} 25^{+}$cells, or CD40-silenced OVA DC-induced $\mathrm{CD} 4^{+} \mathrm{CD} 25^{+}$cells were sensitized and challenged with OVA as described in Methods (treatment on day 1, sensitization on days $2 \& 15$, challenge on days 21-27, sample collection on day 28). The number of sneezes and nasal rubbing movements was counted immediately after the last nasal challenge to examine the effect of these $\mathrm{T}$ cells on nasal allergic symptoms. CD40-silenced OVA DC-induced Tregs significantly decreased the number of sneezes and nasal rubbing movements compared with the other groups (Figure 1A and B). Although CD40-silenced nonantigen DC-induced $\mathrm{T}$ cells at a concentration of $4 \times 10^{5}$ cells/mouse did not reduce these symptoms, CD40-silenced nonantigen DC-induced T cells at levels 10 times greater and more $\left(4 \times 10^{6}\right.$ cells/mouse and $8 \times 10^{6}$ cells/mouse $)$ significantly inhibited these symptoms. However, there were no significant differences in symptom inhibition between CD40silenced nonantigen DC-induced Tregs at levels of $4 \times 10^{6}$ cells/ mouse and $8 \times 10^{6}$ cells/mouse.

Next, the number of eosinophils in the nasal septum was counted to evaluate eosinophilia, which is associated with allergic symptoms and allergic responses in the nose. The number of eosinophils infiltrating the nasal mucosa in mice injected with Tregs induced by CD40-silenced OVA DCs was
A

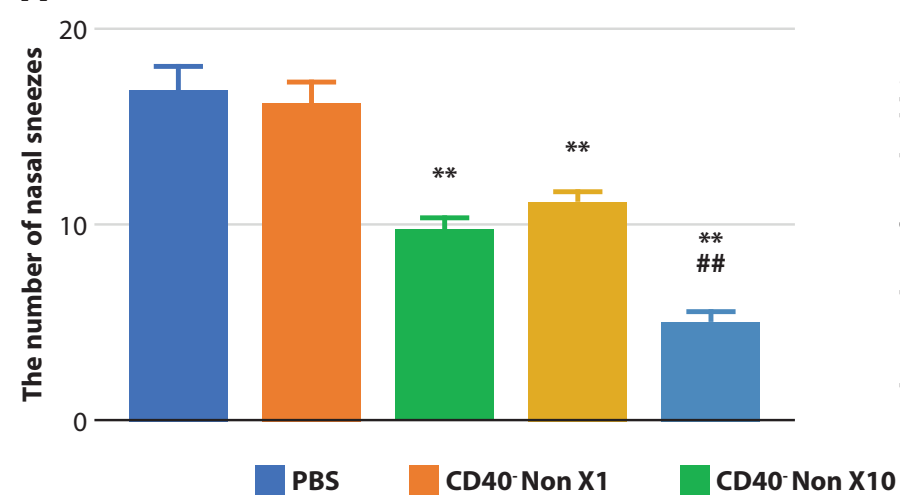

B

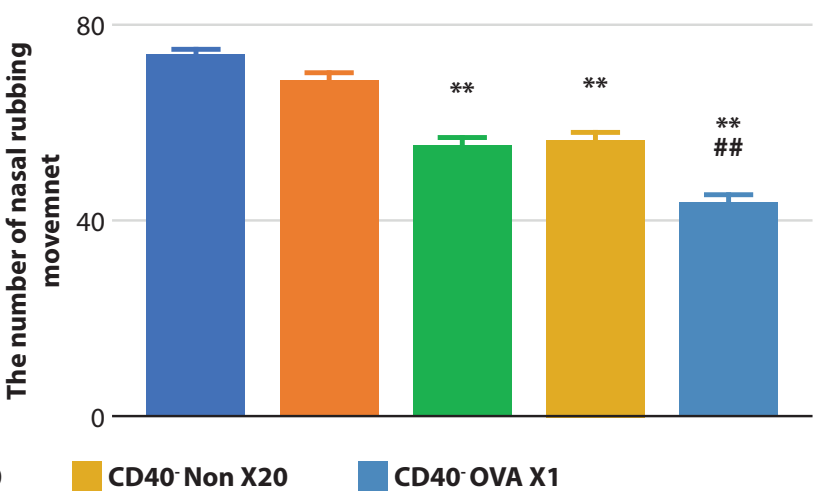

Figure 1. Prevention effects of allergy by $\mathrm{CD}^{+} \mathrm{CD} 25^{+}$cells induced by CD40-silenced OVA DCs.

Five mice were injected intraperitoneally and challenged intranasally with OVA after treatment of PBS alone, CD40-silenced nonantigen DC-induced $\mathrm{CD} 4^{+} \mathrm{CD} 25^{+}$cells (CD40- Non, $4 \times 10^{5}$ "X1", $4 \times 10^{6}$ "X10", or $8 \times 10^{6}$ "X20", cells/mouse), or CD40-silenced OVA DC-induced $\mathrm{CD}^{+} \mathrm{CD} 25^{+}$cells (CD40- OVA, $4 \times 10^{5}$ cells/mouse). The number of sneezes (A) and nasal rubbing movements (B) was counted after the last nasal challenge. 
C

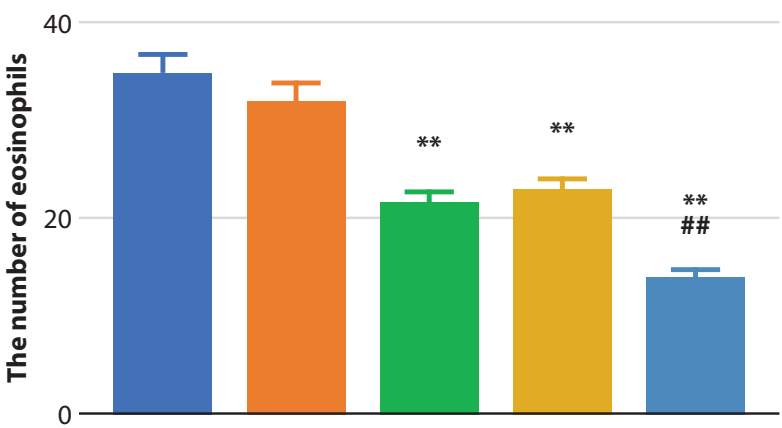

E 150

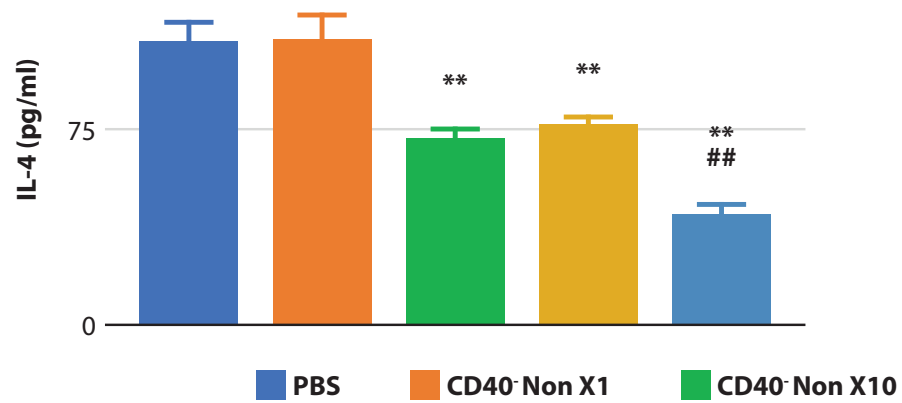

D
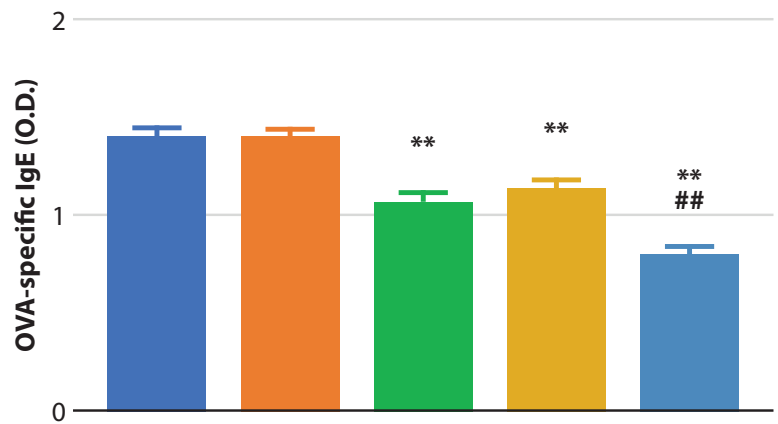

$\mathbf{F}$ 400

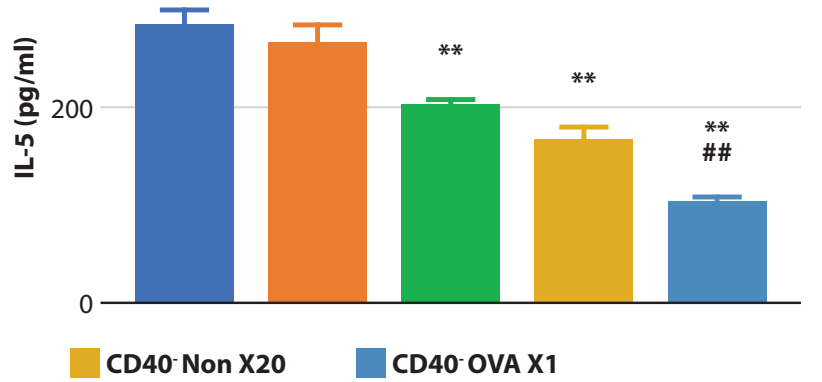

Figure 1. (Continued)

(C) Eosinophilia of the nasal septum. (D) The level of OVA-specific IgE in sera. The level of IL-4 (E) and IL-5 (F) production from splenic splenocytes stimulated by OVA was measured by ELISA. ${ }^{* *} \mathrm{P}<0.01$ versus groups of PBS alone and CD40- Non X1. \#\# $<$ 0.01 versus groups of $\mathrm{CD}_{40}{ }^{-} \mathrm{Non}(\mathrm{X} 10, \mathrm{X} 20)$. Experiments were repeated 3 times with similar result.

significantly fewer than that in mice with PBS alone or Tregs induced by CD40-silenced nonantigen DCs (Figure 1C). CD40-silenced nonantigen DC-induced Tregs at levels of 4 $\times 10^{6}$ cells/mouse or $8 \times 10^{6}$ cells/mouse also significantly inhibited this eosinophilia, whereas CD40-silenced nonantigen DC-induced Tregs at the level of $4 \times 10^{5}$ cells/mouse did not (Figure 1C).

We also measured OVA-specific IgE in sera by ELISA, since $\mathrm{IgE}$ is associated with allergic reactions. CD40-silenced nonantigen DC-induced Tregs at levels of $4 \times 10^{6}$ or $8 \times 10^{6}$ cells/ mouse also significantly suppressed the level of OVA-specific IgE, although CD40-silenced nonantigen DC-induced Tregs at the level of $4 \times 10^{5}$ cells/mouse cells/mouse did not. Tregs produced by CD40-silenced OVA DCs inhibited OVA-specific IgE significantly more than the other groups (Figure 1D). These data suggest that Tregs induced by CD40-silenced OVA DCs prevent production of OVA-specific IgE.

IL-4 and IL-5 play important roles in the development of allergic diseases. In order to investigate the effect of Tregs induced by CD40-silenced OVA DCs on cytokine production, we measured the production of IL- 4 and IL- 5 from splenic T cells stimulated with OVA in vitro. There were no significant differences between mice received PBS alone and CD40-silenced nonantigen DC-induced Tregs at levels of $4 \times 10^{5}$ cells/ mouse in the productions of IL-4 and IL-5. The levels of IL-4 and IL- 5 produced in mice that received Tregs induced by CD40-silenced OVA DCs were significantly lower than those in mice that received PBS or Tregs induced by CD40-silenced nonantigen DCs (Figure 1E and F). This suggests that OVAspecific Tregs suppress the production of Th2 cytokines, which may contribute to the prevention of allergy.

\section{No preventive effect of Tregs induced by CD40-silenced OVA DCs on KLH-induced allergy}

To investigate antigen specificity, we examined whether Tregs induced by CD40-silenced OVA DCs in vitro can inhibit allergic responses and symptoms caused by KLH. Mice received PBS, CD40-silenced nonantigen DC-induced Tregs, or CD40-silenced OVA DC-induced Tregs were sensitized and challenged with $\mathrm{KLH}$ as described in Methods (treatment on day 1 , sensitization on days 2 \& 15, challenge on days 21-27, sample collection on day 28). Administration of Tregs induced by CD40-silenced OVA DCs did not significantly inhibit the number of nasal sneezes, nasal rubbing movements, or eosinophils at the nasal septum and the level of KLH-specific IgE in sera compared with mice that received PBS alone (Figure 2A-D). These findings suggest that Tregs induced by CD40silenced OVA DCs inhibit allergen reactions and symptoms in an antigen-specific manner.

Administration of CD40-silenced nonantigen DC-induced Tregs $\left(4 \times 10^{6}\right.$ cells/mouse $)$ inhibited the number of nasal sneezes, nasal rubbing movements, and eosinophils at the nasal mucosa and KLH-specific IgE levels in sera compared with the other groups (Figure 2A-D). These results suggest 
A

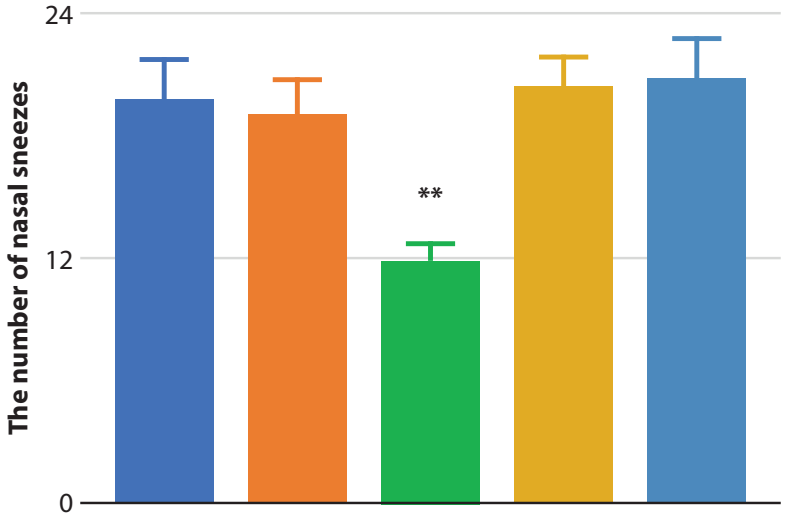

C

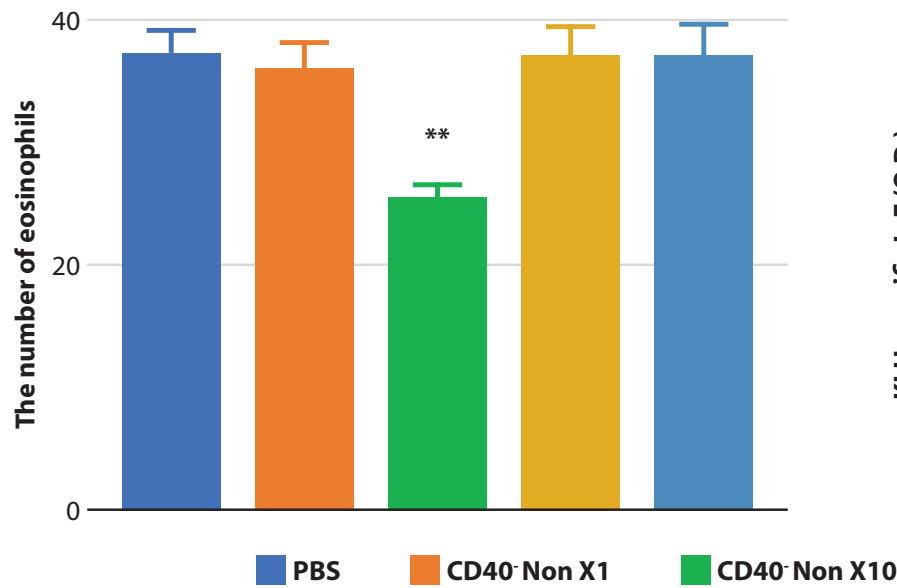

$\mathbf{B}$

90

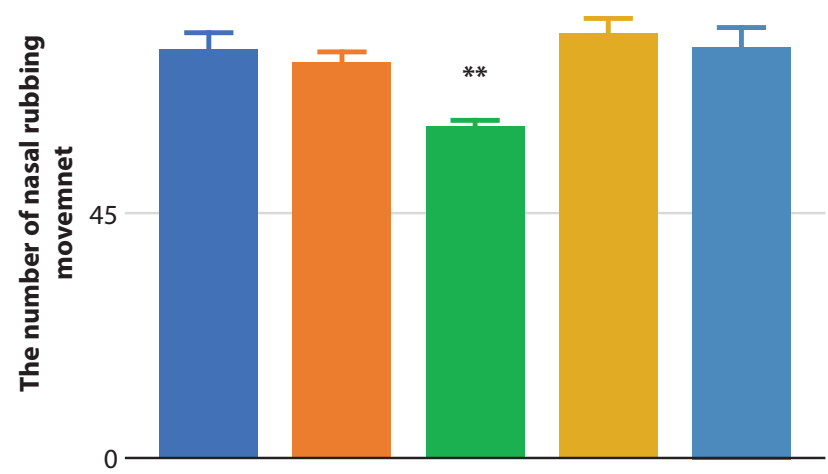

D
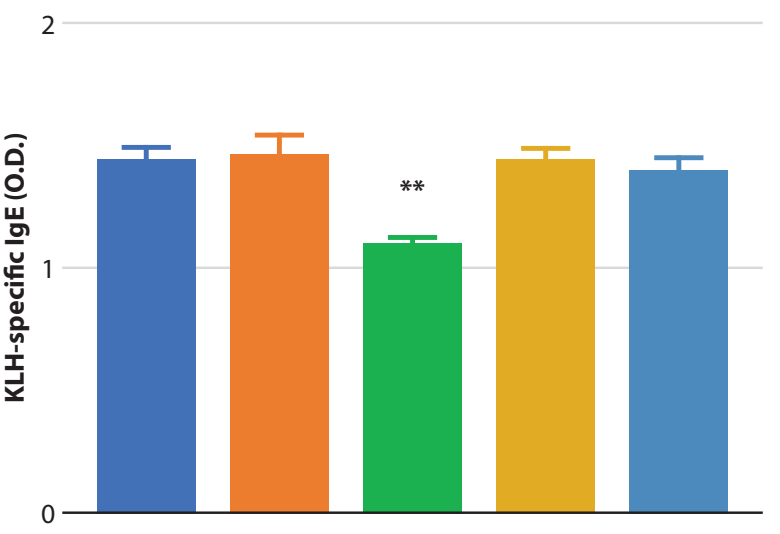

CD40- Non X20 CD40- OVA X1

Figure 2. No allergy prevention effect from $\mathrm{CD} 4{ }^{+} \mathrm{CD} 25^{+}$Tregs induced by CD40-silenced OVA DCs.

Five mice were injected intraperitoneally and challenged intranasally with KLH after treatment with PBS alone, CD40-silenced nonantigen DC-induced CD4 ${ }^{+} \mathrm{CD} 25^{+}$cells (CD40- Non, $4 \times 10^{5}$ "X1" or $4 \times 10^{6}$ "X10" cells/mouse), or CD40-silenced OVA DC-induced $\mathrm{CD}^{+} \mathrm{CD} 25^{+}$cells $\left(\mathrm{CD} 40^{-} \mathrm{OVA}, 4 \times 10^{5}\right.$ "X1" or $4 \times 10^{6}$ "X10" cells/mouse). The numbers of sneezes (A) and nasal rubbing movements (B) were counted after the last nasal challenge. (C) Eosinophilia of the nasal septum. (D) The level of KLH-specific IgE in sera. ${ }^{\star *} \mathrm{P}<0.01$ versus groups of PBS alone, CD40- Non X1, and CD40- OVA (X1, X10). Experiments were repeated 3 times with similar result.

A

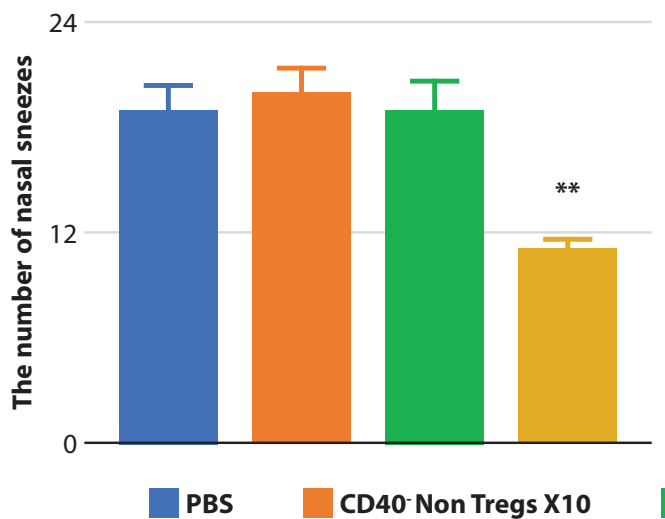

B

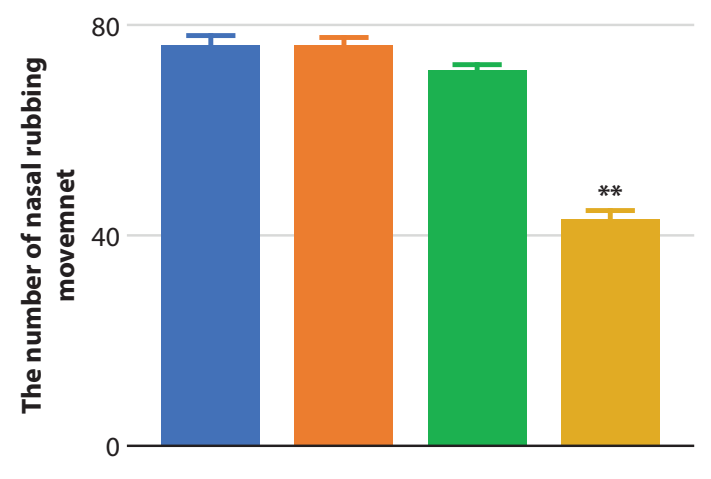

CD40- Non Tregs X20

CD40- OVA Tregs X1

Figure 3. Therapeutic effects of $\mathrm{CD}^{+}{ }^{+} \mathrm{CD} 25^{+}$Tregs induced by CD40-silenced OVA DCs in vitro on established allergic rhinitis. Five mice with OVA-induced allergic rhinitis were treated with PBS alone, CD40-silenced nonantigen DC-induced CD4 ${ }^{+} \mathrm{CD} 25^{+}$cells (CD40- Non, $4 \times 10^{6}$ "X10" or $8 \times 10^{6}$ "X20" cells/mouse), or CD40-silenced OVA DC-induced CD4 ${ }^{+} \mathrm{CD} 25^{+}$cells $\left(4 \times 10^{5}\right.$ "CD40OVA X1" cells/mouse). The number of sneezes (A) and nasal rubbing movements (B) was counted after the last nasal challenge. 
C

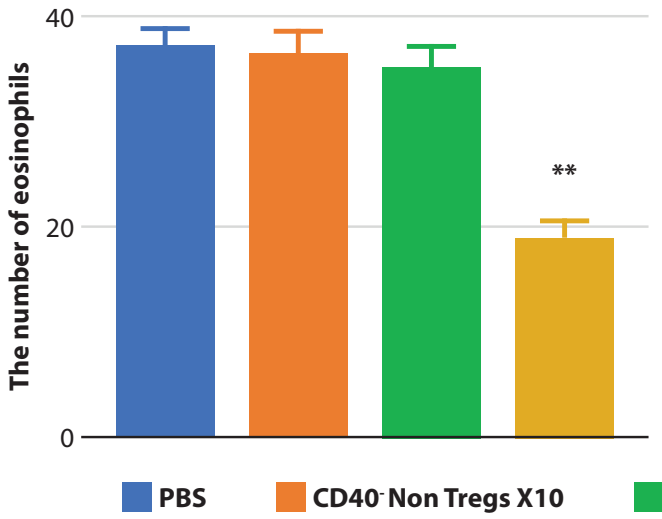

D
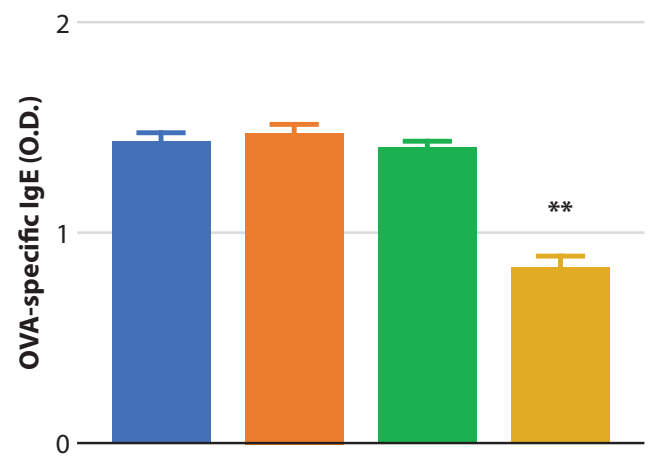

CD40-Non Tregs X20

CD40 OVA Tregs X1

Figure 3. (Continued)

(C) Eosinophilia of the nasal septum. (D) The level of OVA-specific IgE in sera. ${ }^{* *} \mathrm{P}<0.01$ versus group of PBS alone, $\mathrm{CD}^{*} 0^{-}$Non X10, and CD40- Non X20. Experiments were repeated 3 times with similar result.

that CD40-silenced nonantigen DC-induced Tregs are not antigen-specific.

\section{Therapeutic effects of Tregs induced by CD40-silenced OVA} DCs on mice with established OVA-induced allergic rhinitis

Mice with established allergic rhinitis were treated with PBS alone, CD40-silenced nonantigen DC-induced Tregs, or CD40-silenced OVA DC-induced Tregs. After treatment, nasal re-challenge with OVA was performed (sensitization on days 1 \& 14, nasal challenge on days 18-24, treatment with Tregs on day 26, nasal re-challenge on days 27-32, sample collection on day 33). The number of sneezes and nasal rubbing movements on day 24 was significantly higher than on day 17 (data not shown). Eosinophils in the nasal septum were seen on day 24, although no eosinophilia was found on day 17 (data not shown). These results suggest that mice were suffering from allergic rhinitis on day 24 . There were no significant effects on the number of sneezes, nasal rubbing movements, or eosinophils in the nasal mucosa, or the level of OVA-specific IgE in sera, even when CD40-silenced nonantigen DC-induced Tregs $\left(8 \times 10^{6}\right.$ cells/mouse) were injected (Figure 3A-D).

Tregs induced by CD40-silenced OVA DCs in vitro significantly reduced the number of sneezes, nasal rubbing movements, and eosinophils in the nasal mucosa, and the level of OVA-specific IgE in sera, compared with the other groups, PBS alone, and Tregs induced by CD40-silenced nonantigen DCs (Figure 3A-D). These findings suggest that Tregs induced by CD40-silenced OVA DCs are therapeutically useful even for mice with established allergic rhinitis.

Immune regulatory properties of Tregs induced by DCs (CD40-silenced Cry $\mathrm{j} 1 \mathrm{DCs}$ ) transfected with CD40 siRNA and pulsed with Cry $\mathrm{j} 1$

Next, we investigated Tregs induced by CD40-silenced DCs (CD40-silenced Cry j 1 DCs) pulsed with Cry j 1 but not OVA, because OVA is a food allergen but not aeroallergen. Cry $\mathrm{j} 1$ is one of the major allergens of Japanese cedar pollen which cause severe allergic diseases in Japan. ${ }^{15-19}$ Bone marrow-derived DCs were transfected with CD40 siRNA or Control siRNA (Control DCs). DCs transfected with CD40 siRNA were pulsed
A

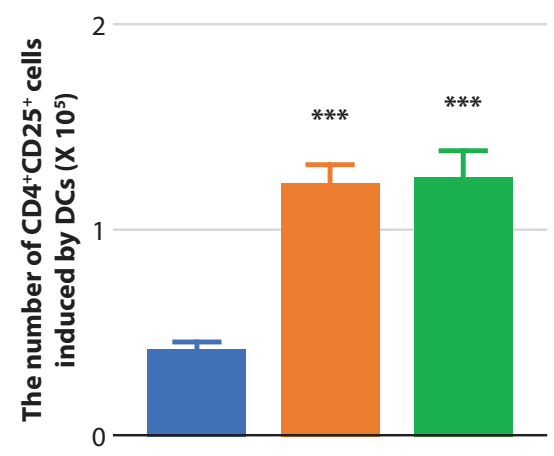

B

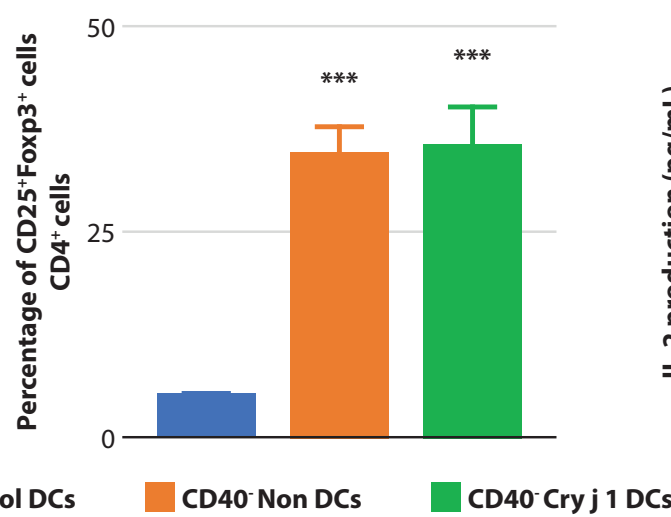

C

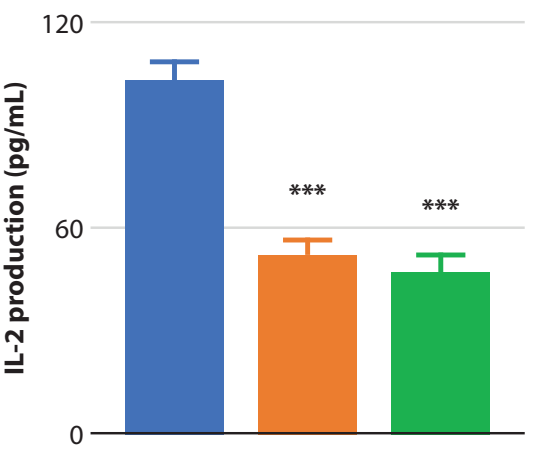

Figure 4. Modulation by CD40 siRNA in vitro. (A) DCs were transfected with Control siRNA (Control DCs) or CD40 siRNA. DCs transfected with CD40 siRNA were pulsed without Cry j 1 (CD40- Non DCs) or with Cry j 1 (CD40- Cry j 1 DCs). The numbers of $\mathrm{CD} 4^{+} \mathrm{CD} 25^{+}$cells induced from $3 \times 10^{5}$ naïve $\mathrm{CD}^{+}$cells by Control DCs, CD40- Cry j 1 DCs, and CD40- Non DCs were examined. (B) The percentage of CD25 $5^{+}$Foxp $3^{+} \mathrm{T}$ cells in $\mathrm{CD}^{+} \mathrm{T}$ cells after co-culture of T cells and DCs. (C) Quantity of IL- 2 production after co-culture of T cells and DCs. ${ }^{* *} \mathrm{P}<0.001$ versus group of Control DCs. Experiments were repeated 3 times with similar result. 
with Cry j 1 (CD40-silenced Cry j 1 DCs) or no antigen (CD40-silenced nonantigen DCs). Naïve T cells, separated from splenic $\mathrm{T}$ cells in naïve mice as described in Methods, were co-cultured with Control DCs, CD40-silenced nonantigen DCs, or CD40-silenced Cry j 1 DCs. Although we assessed the number of $\mathrm{CD} 4{ }^{+} \mathrm{CD} 25^{+}$cells were induced from $3 \times 10^{5}$ naïve $\mathrm{CD} 4^{+}$cells, the number of $\mathrm{CD} 4^{+} \mathrm{CD} 25^{+}$cells induced by CD40-silenced Cry j 1 DCs or CD40-silenced nonantigen DCs were significantly higher than that by Control DCs. (Figure 4A). The percentage of $\mathrm{CD}^{2} 5^{+} \mathrm{Foxp}^{+}$cells in $\mathrm{CD}^{+} \mathrm{T}$ cells induced by CD40-silenced nonantigen DCs and CD40-silenced Cry j 1 DCs were significantly higher compared with those induced by Control DCs (Figure 4B). And we investigated whether $\mathrm{CD}^{+} \mathrm{CD}^{2} 5^{+}$cells induced by $\mathrm{CD} 40$-silenced Cry j 1 DCs could affect IL-2 production in order to examine the mechanism of Treg induction, since the association between IL-2 production and Treg expansion has been reported. ${ }^{20,21}$ Cry j 1-specific $\mathrm{T}$ cell response was generated by a co-culture of DCs and $\mathrm{CD}^{+} \mathrm{CD} 25^{-} \mathrm{T}$ cells isolated from the spleen in mice sensitized with Cry j 1 antigen. Quantity of IL-2 in the supernatant was measured by ELISA. Consequently, IL-2 production

A

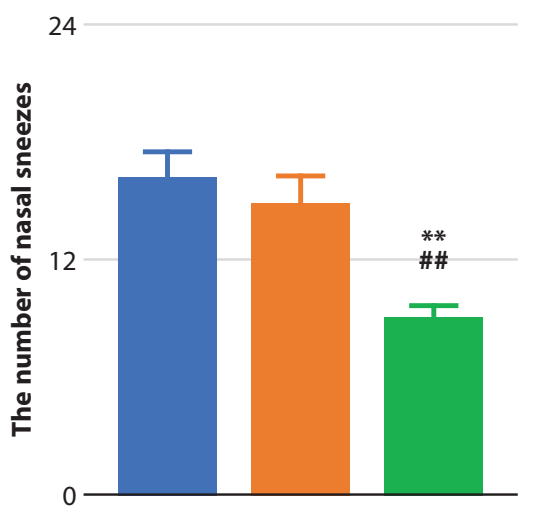

C

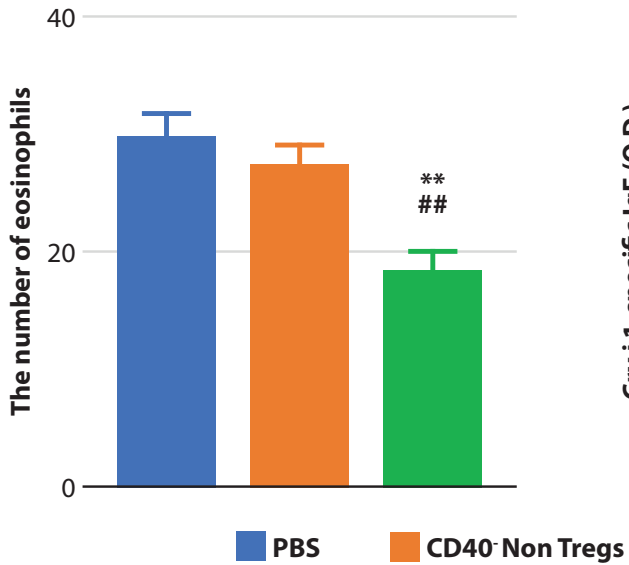

was significantly inhibited by CD40-silenced nonantigen DCs or CD40-silenced Cry j 1 DCs (Figure 4C).

Therapeutic effects of Tregs induced by CD40-silenced Cry $\mathrm{j} 1$ DCs on mice with established Cry j 1-induced allergic rhinitis

We assessed the effects of siRNA-induced Tregs on allergic diseases caused by aeroallergen, Japanese cedar pollen. Mice with allergic rhinitis were treated with PBS alone, CD40-silenced nonantigen DC-induced Tregs, or CD40-silenced Cry $j$ 1 DC-induced Tregs. After treatment, nasal re-challenge with Cry j 1 was performed (sensitization on days 1 \& 14, nasal challenge on days 18-24, treatment with Tregs on day 26, nasal re-challenge on days 27-32, sample collection on day 33). No eosinophilia in the nasal septum was found on day 17 , whereas eosinophilia was seen on day 24 (data not shown). The numbers of sneezes and nasal rubbing movements on day 24 were significantly higher than those on day 17 (data not shown). These suggest that allergic rhinitis was established on day 24. After treatment with CD40-silenced nonantigen DC-induced Tregs, there were no significant effects on the number of sneezes, nasal rubbing movements, eosinophilia in the nasal mucosa, and

B

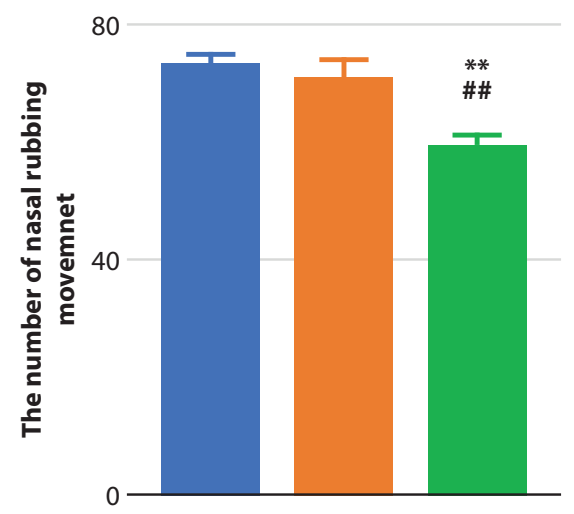

D

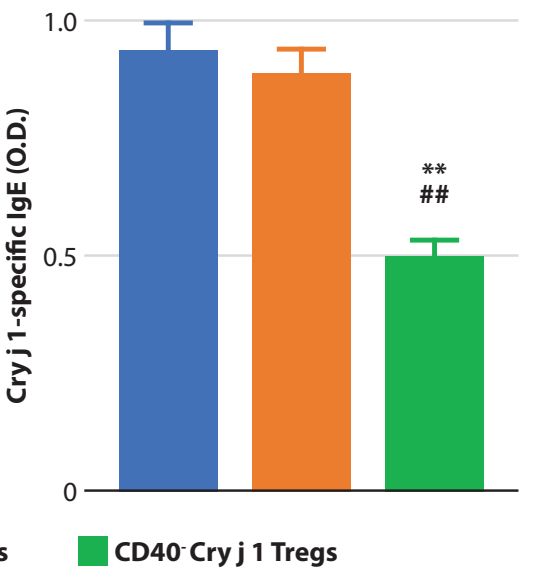

Figure 5. Therapeutic effects of $\mathrm{CD}^{+} \mathrm{CD} 25^{+}$Tregs induced by CD40-silenced Cry 1 1 DCs in vitro on established allergic rhinitis. Five mice with Cry j 1-induced allergic rhinitis were treated with PBS alone, CD40-silenced nonantigen DC-induced CD4 ${ }^{+} \mathrm{CD} 25^{+}$ cells $\left(8 \times 10^{6}\right.$ cells/mouse, CD40- Non Tregs) or CD40-silenced Cry j 1 DC-induced CD ${ }^{+} \mathrm{CD} 25^{+}$cells $\left(4 \times 10^{5}\right.$ cells/mouse, CD 40 Cry j 1 Tregs). The number of sneezes (A) and nasal rubbing movements (B) was counted after the last nasal challenge. (C) Eosinophilia of the nasal septum. (D) The level of Cry j 1-specific IgE in sera. ${ }^{* *} \mathrm{P}<0.01$ versus group of $\mathrm{PBS}$ alone, \#\# $\mathrm{P}<0.01$ versus group of CD40- Non Tregs. Experiments were repeated 3 times with similar result. 
the level of Cry j 1-specific IgE in sera (Figure 5A-D). However, Tregs induced by CD40-silenced Cry $\mathrm{j} 1$ DCs in vitro significantly reduced the number of sneezes, nasal rubbing movements, and eosinophilia in the nasal mucosa, and the level of Cry j 1-specific IgE in sera, compared with other groups, PBS alone, and Tregs induced by CD40-silenced nonantigen DCs (Figure 5A-D). These findings suggest that Tregs induced by CD40-silenced Cry j 1 DCs are therapeutically useful for mice with allergic rhinitis caused by Japanese cedar pollen.

\section{Discussion}

Administration of Tregs induced by CD40-silenced nonantigen DCs before sensitization significantly reduced allergic responses and symptoms not only in OVA-induced allergy but also in KLH-induced allergy. These results suggest that Tregs induced by CD40-silenced nonantigen DCs are antigen-nonspecific Tregs. Patients who suffer from sensitization to multiple allergens are increasing. ${ }^{22}$ Antigen-specific therapy for these patients is not easy, nor is it applicable for patients with an unknown causative allergen. Thus, CD40 silenced nonantigen DC-induced Tregs may be an alternative, antigen-independent therapy for the prevention of allergic diseases.

Although blockade of CD40-CD40L interaction induce Tregs, ${ }^{4,23}$ the underlying mechanism of Treg expansion by blockade of CD40-CD40L is not known. ${ }^{24}$ However, low-dose IL-2 expands $\mathrm{CD}^{+}$regulatory $\mathrm{T}$ cells with a suppressive function in vitro. ${ }^{21}$ Both blockade of B7-CD28 and CD40-CD40L also activated Foxp $3^{+}$regulatory $\mathrm{T}$ cells and reduced IL-2 production. ${ }^{20}$ When $\mathrm{CD} 25^{+} \mathrm{CD} 4^{+} \mathrm{T}$ cells compete with other cells for $\mathrm{IL}-2, \mathrm{CD} 4^{+} \mathrm{CD} 25^{+} \mathrm{T}$ cells further up-regulate the CD25 (IL-2R alpha chain). ${ }^{25}$ And Vogel et al. ${ }^{20}$ assumed that the low amount of IL- 2 is enough for the survival of CD $4^{+}$Foxp $3^{+}$ cells, but not enough for the survival of $\mathrm{CD} 4^{+}$Foxp 3 cells. This study showed that blockade of only CD40-CD40L pathway inhibited IL-2 productions. These suggest that blockade of CD40-CD40L induces expansion of $\mathrm{CD} 4{ }^{+}$Foxp $3^{+}$Tregs through reduction of IL-2 production.

We previously reported that CD40-silenced OVA DCs inhibited allergic reactions and symptoms. However, CD40-silenced OVA DCs may induce unexpected problems in vivo. CD40 siRNA may go out of DCs and induce problems such as inhibition of CD40 gene on other cells, interferon response, and off-target effect, although these have been not reported. If deficiency of CD40-CD40L interaction occurs in vivo, this may lead susceptibility to infection ${ }^{26,27}$ like hyper IgM syndrome. ${ }^{28}$ dsRNA, less than 30 bp in length, are generally believed to avoid interferon responses. ${ }^{29}$ However, interferon response should be paid attention to even in siRNA, since siRNA could interferon response ${ }^{30,31}$ and since the threshold of dsRNA length to induce interferon responses varies by cell types. ${ }^{29}$ In future, various Treg phenotype may be revealed. Even if siRNA-induced Tregs include various Treg phenotype, it may be possible to collect only specific phenotype before administration in time to come. The advantages of this novel therapy with siRNA-induced Tregs presented herein include: 1) no interferon responses caused by siRNA; 2) no off-target effects by siRNA; 3) no inhibition of CD40 gene expression in vivo by CD40 siRNA; 4) no unexpected problems by siRNA or
siRNA-transfected DCs; 5) higher stability in the numbers of siRNA-induced Tregs administered (induction of Tregs by CD40-silenced DCs is not always the same by the conditions in vivo), and 6) possibility to select specific Treg phenotype before administration, compared with therapy with siRNAtransfected DCs. On the other hand, the advantages of therapy with siRNA-transfected DCs presented herein include: 1) less time for preparation in vitro, 2) less cost, and 3) possibilities of tolerance, anergy, and apoptosis by modified DCs, ${ }^{32-34}$ compared with therapy with siRNA-induced Tregs.

In this study, we report a novel antigen-specific therapy for the control of allergic diseases, using Tregs induced by CD40-silenced antigen-specific DCs transfected with CD40 siRNA in vitro, and siRNA-induced antigen-nonspecific Tregs for the prevention of allergic diseases. Furthermore, antigen -specific Tregs induced by siRNA-modulated DCs are attractive since they have more potent inhibiting effects on allergic responses and symptoms than antigen non-specific Tregs.

\section{Financial disclosure}

This study is partially supported by Grants-in-Aid for Scientific Research C (15K10789) from Japan Society for the Promotion of Science.

\section{Conflict of interest \\ None}

\section{Authors' contributions}

Motohiko Suzuki and Yoshihisa Nakamura designed the study. Motohiko Suzuki and Makoto Yokota wrote the manuscript. Makoto Yokota and Shinya Ozaki contributed to data collection. Shinya Ozaki and Yoshihisa Nakamura performed the statistical analysis and interpretation of the results. All authors read and approved the final manuscript.

\section{References}

1. Kirk AD, Blair PJ, Tadaki DK, Xu H, Harlan DM. The role of CD154 in organ transplant rejection and acceptance. Philos Trans R Soc Lond B Biol Sci. 2001;356:691-702.

2. Lanschuetzer CM, Olasz EB, Lazarova Z, Yancey KB. Transient anti-CD40L co-stimulation blockade prevents immune responses against human bullous pemphigoid antigen 2: implications for gene therapy. J Invest Dermatol. 2009;129:1203-7.

3. Blazar BR, Taylor PA, Panoskaltsis-Mortari A, Buhlman J, Xu J, Flavell RA, et al. Blockade of CD40 ligand-CD40 interaction impairs CD4 ${ }^{+} \mathrm{T}$ cell -mediated alloreactivity by inhibiting mature donor $\mathrm{T}$ cell expansion and function after bone marrow transplantation. J Immunol. 1997;158:29-39.

4. Taylor PA, Friedman TM, Korngold R, Noelle RJ, Blazar BR. Tolerance induction of alloreactive $\mathrm{T}$ cells via ex vivo blockade of the CD40:CD40L costimulatory pathway results in the generation of a potent immune regulatory cell. Blood. 2002;99:4601-9.

5. Hill JA, Ichim TE, Kusznieruk KP, Li M, Huang X, Yan X, et al. Immune modulation by silencing IL-12 production in dendritic cells using small interfering RNA. J Immunol. 2003;171:691-6.

6. Bertrand JR, Pottier M, Vekris A, Opolon P, Maksimenko A, Malvy C Comparison of antisense oligonucleotides and siRNAs in cell culture and in vivo. Biochem Biophys Res Commun. 2002;296:1000-4.

7. Celotto AM, Lee JW, Graveley BR. Exon-specific RNA interference: a tool to determine the functional relevance of proteins encoded by alternatively spliced mRNAs. Methods Mol Biol. 2005;309:273-82.

8. Grishok A, Tabara H, Mello CC. Genetic requirements for inheritance of RNAi in C. elegans. Science. 2000;287:2494-7. 
9. Suzuki M, Zheng X, Zhang X, Li M, Vladau C, Ichim TE, et al. Novel vaccination for allergy through gene silencing of CD40 using small interfering RNA. J Immunol. 2008;180:8461-9.

10. Suzuki M, Zheng X, Zhang X, Ichim TE, Sun H, Kubo N, et al. Inhibition of allergic responses by CD40 gene silencing. Allergy. 2009;64:387-97.

11. Suzuki M, Zheng X, Zhang X, Zhang ZX, Ichim TE, Sun H, et al. A novel allergen-specific therapy for allergy using CD40-silenced dendritic cells. J Allergy Clin Immunol. 2010;125:737-43, 43 e1-43 e6.

12. Fantini MC, Dominitzki S, Rizzo A, Neurath MF, Becker C. In vitro generation of $\mathrm{CD} 4{ }^{+} \mathrm{CD} 25^{+}$regulatory cells from murine naive T cells. Nat Protoc. 2007;2:1789-94.

13. Zhang D, Chen Z, Wang DC, Wang X. Regulatory T cells and potential inmmunotherapeutic targets in lung cancer. Cancer Metastasis Rev. 2015; 34:277-90.

14. Zhao C, Shi G, Vistica BP, Hinshaw SJ, Wandu WS, Tan C, et al. Induced regulatory T-cells (iTregs) generated by activation with anti-CD3/CD28 antibodies differ from those generated by the physiological-like activation with antigen/APC. Cell Immunol. 2014;290:179-84.

15. Suzuki M, Komiyama N, Itoh M, Itoh H, Sone T, Kino K, et al. Purification, characterization and molecular cloning of Cha o 1, a major allergen of Chamaecyparis obtusa (Japanese cypress) pollen. Mol Immunol. 1996; 33:451-60.

16. Yasueda H, Yui Y, Shimizu T, Shida T. Isolation and partial characterization of the major allergen from Japanese cedar (Cryptomeria japonica) pollen. J Allergy Clin Immunol. 1983;71:77-86.

17. Suzuki M, Itoh H, Sugiyama K, Takagi I, Nishimura J, Kato K, et al. Causative allergens of allergic rhinitis in Japan with special reference to silkworm moth allergen. Allergy. 1995;50:23-7.

18. Gotoh M, Yuta A, Okano M, Ohta N, Matsubara A, Okubo K. Severity assessment of Japanese cedar pollinosis using the practical guideline for the management of allergic rhinitis in Japan and the allergic rhinitis and its impact on asthma guideline. Allergol Int. 2013;62:181-9.

19. Fujimura T, Kawamoto S. Spectrum of allergens for Japanese cedar pollinosis and impact of component-resolved diagnosis on allergen-specific immunotherapy. Allergol Int. 2015;64:312-20.

20. Vogel I, Verbinnen B, Maes W, Boon L, Van Gool SW, Ceuppens JL. Foxp3 ${ }^{+}$ regulatory $\mathrm{T}$ cells are activated in spite of B7-CD28 and CD40-CD40L blockade. Eur J Immunol. 2013;43:1013-23.

21. Li Y, Liu X, Wang W, Wang S, Zhang J, Jiang S, et al. Low-dose IL-2 expands CD4(+) regulatory $\mathrm{T}$ cells with a suppressive function in vitro via the STAT5-dependent pathway in patients with chronic kidney diseases. Ren Fail. 2018;40:280-8.

22. Arbes SJ, Jr., Gergen PJ, Elliott L, Zeldin DC. Prevalences of positive skin test responses to 10 common allergens in the US population: results from the third National Health and Nutrition Examination Survey. J Allergy Clin Immunol. 2005; 116:377-83.
23. Jiang X, Sun W, Guo D, Cui Z, Zhu L, Lin L, et al. Cardiac allograft acceptance induced by blockade of CD40-CD40L costimulation is dependent on $\mathrm{CD} 4{ }^{+} \mathrm{CD} 25^{+}$regulatory T cells. Surgery. 2011;149:336-46.

24. VogelI, Verbinnen B, Van GoolS, Ceuppens JL. Regulatory T Cell-Dependent and -Independent Mechanisms of Immune Suppression by CD28/B7 and CD40/CD40L Costimulation Blockade. J Immunol. 2016;197:533-40.

25. Barthlott T, Moncrieffe H, Veldhoen M, Atkins CJ, Christensen J, O'Garra A, et al. CD $25^{+} \mathrm{CD} 4^{+} \mathrm{T}$ cells compete with naive $\mathrm{CD} 4^{+} \mathrm{T}$ cells for IL-2 and exploit it for the induction of IL-10 production. Int Immunol. 2005; 17: 279-88.

26. Kamanaka M, Yu P, Yasui $T$, Yoshida $K$, Kawabe $T$, Horii $T$, et al. Protective role of CD40 in Leishmania major infection at two distinct phases of cell-mediated immunity. Immunity. 1996;4:275-81.

27. Al-Saud BK, Al-Sum Z, Alassiri H, Al-Ghonaium A, Al-Muhsen S, Al-Dhekri H, et al. Clinical, immunological, and molecular characterization of hyper-IgM syndrome due to CD40 deficiency in eleven patients. J Clin Immunol. 2013;33:1325-35.

28. Winkelstein JA, Marino MC, Ochs H, Fuleihan R, Scholl PR, Geha R, et al The X-linked hyper-IgM syndrome: clinical and immunologic features of 79 patients. Medicine (Baltimore). 2003;82:373-84.

29. Reynolds A, Anderson EM, Vermeulen A, Fedorov Y, Robinson K, Leake D, et al. Induction of the interferon response by siRNA is cell type- and duplex length-dependent. RNA. 2006;12:988-93.

30. Kim DH, Longo M, Han Y, Lundberg P, Cantin E, Rossi JJ. Interferon induction by siRNAs and ssRNAs synthesized by phage polymerase. Nat Biotechnol. 2004;22:321-5.

31. Ebert G, Poeck H, Lucifora J, Baschuk N, Esser K, Esposito I, et al. 5 Triphosphorylated small interfering RNAs control replication of hepatitis $B$ virus and induce an interferon response in human liver cells and mice. Gastroenterology. 2011;141:696-706.

32. Lu L, Li W, Zhong C, Qian S, Fung JJ, Thomson AW, et al. Increased apoptosis of immunoreactive host cells and augmented donor leukocyte chimerism, not sustained inhibition of B7 molecule expression are associated with prolonged cardiac allograft survival in mice preconditioned with immature donor dendritic cells plus anti-CD40L mAb. Transplantation. 1999;68:747-57.

33. Kuwana M. Induction of anergic and regulatory $\mathrm{T}$ cells by plasmacytoid dendritic cells and other dendritic cell subsets. Hum Immunol. 2002;63: 1156-63.

34. Nouri-Shirazi M, Guinet E. Direct and indirect cross-tolerance of alloreactive $\mathrm{T}$ cells by dendritic cells retained in the immature stage. Transplantation. 2002; 74: 1035-44 


\section{Instructions for authors}

NEW author guidelines for APIAI

(effective as of February 1, 2017)

Please submit your manuscript via on-line submission system at the following address: http://www.apjai-journal.org.

\section{Mission Statement}

The Asian Pacific Journal of Allergy and Immunology (APJAI) publishes original research articles, clinical observations, case reports and reviews on various aspects of allergy and immunology provided that they have not been, and will not be, published elsewhere in whole, or in part, without the Editor's permission. Papers accepted become the copyright of the Journal. Authors are responsible for all statements in articles submitted to the APJAI.

\section{Journal Publication Policies and Procedures}

The APJAI will consider for publication those papers directly related to allergy and immunology and has agreed to follow the Uniform Requirements for Manuscripts Submitted to Biomedical Journals (the "Uniform Requirements") of the International Committee of Medical Journal Editors (ICMJE), the full text of which is available at http://www.icmje.org. The manuscript submission instructions for the APJAI submission are consistent with the 2009 version of the Uniform Requirements. The Editor assumes that upon submission of a manuscript, all listed authors have agreed with the APJAI policies. Manuscripts that do not meet these guidelines will be returned to the submitting author for revision prior to any further consideration for peer review.

Submissions will be considered for publication in APJAI only if they are submitted solely to APJAI. It must not have been previously published and must not be under consideration for publication elsewhere. All published manuscripts become the permanent property of the APJAI and may not be published elsewhere without written permission.

\section{Ethical Approval of Studies and Informed Consent}

For all research studies involving human subjects or research material derived from humans, a statement describing approval by the appropriate Institutional Review Board (IRB) is required in the Methods Section. Authors must declare how and if the informed consents were obtained from the study participants, if the study is conducted in humans, in the Methods Section. Studies exempted from IRB approval by their respective boards should be indicated in the Methods Section. Institutional Review Board approval and informed consent statements are not required for Case Reports. Studies involving experimental animals must include a statement in the Methods Section indicating that institutional or national guidelines were followed for the care and use of the animals. Failure to comply with this requirement will result in the manuscript being returned without review.

\section{Clinical Trial Registration}

APJAI requires investigators to preregister their clinical trials in a public trials registry approved by WHO (http://www. who.int/ictrp/network/primary/en/).

APJAI has adopted the WHO's definition of a clinical trial: "any research study that prospectively assigns human participants or groups of humans to one or more health-related interventions to evaluate the effects on health outcomes." The clinical trial registration number and name of the registry should be clearly identified on the title page and in the Methods Section.

\section{Manuscript Preparation and Submission Requirements (NEW!!)}

The authors must submit the cover letter, title page, abstract, manuscript text, tables, figures, and/or supplement files. Please read the instruction in the online submission system carefully as many changes have been implemented. All manuscripts are subjected to open peer-review.

Before submitting a manuscript, please gather the following information:

- All Author

- First and Last Names

- Postal Addresses

- Work Telephone Numbers (for Corresponding Author only)

- E-mail addresses

- Title (you can copy and paste this from your manuscript)

- Abstract (you can copy and paste this from your manuscript)

- Manuscript files in Word (Please make sure the "Language" is "English (U.S.)" via Tools->Language->Set Language), WordPerfect, EPS, text, Postscript, PDF, or RTF format.

- Cover Letter, including job title and institution for EVERY Author listed on the manuscript.

- Figures/Images should be in TIFF, GIF, JPG, PDF, Postscript, or EPS format.

Submission Process

The four steps of the submission process are: Files, Manuscript Information, Validate, and Submit. The four steps each contain sub-steps that can be accessed by clicking on their respective tabs. Navigating through this "Tab View" will save any entered information each time a new tab is clicked (or the boxes "Save and Continue" and "Next" are clicked). Each step and sub-step is listed below:

1. Files

- Upload Files

A screen asking for the actual file locations (via an open file dialog) will appear. After completing this screen, your files will be sent to be converted to PDF for the peer review process.

- Remove Files files.

Allows the user to remove previously uploaded

\section{- Replace Files}

Allows the user to replace any previously submitted files with another file.

- File Type

This tab prompts the user to choose the "file type" that corresponds to the upload document. Though the file types can vary from journal to journal, the five basic types of files are, Author Cover Letter, Article File, Figure, Table, Supplemental Material. 


\section{- File Description}

When uploading a file type labeled "Figure", "Table", or "Supplemental Material" it is required to give a brief description of the content that is included in the file.

\section{- File Order}

This tab allows the user to rearrange files to be displayed at the author's discretion. This tab also gives the option to merge PDF files into a single PDF file to display to the Editor and Reviewers. Upon completion the user must check the checkbox indicating completion of the ordering and selection process.

\section{Manuscript Information}

- Title, Abstract

It is require for the user to provide a Title for manuscript as well as a Running Title and an Abstract. The Title, Running Title, and Abstract all have word or character limits. (See details in Manuscript Format)

\section{- Authors}

This tab prompts the user to submit General Information about the author. The fields marked with an asterisk $\left(^{*}\right)$ are required, and need to be completed to continue the submission process.

\section{- Keywords \& Subject Areas}

A screen where the author provides at subject areas of the manuscript from the list provided. If needed, the author can provide keywords for the manuscript by typing it in any boxes that might be provided.

\section{- Detailed Information}

This screen asks for more detailed information regarding the manuscript. Though the questions in this tab may vary from journal to journal, typical questions include "Conflict of Interest" and "Dual Publication".

\section{- Author Review Suggestions}

This screen allows the user to provide "suggested reviewers" to include for the revision process. The author can also provide reviewers to exclude from the revision process.

\section{Validate}

\section{- Approve Files}

The screen allows the user to verify that the manuscript has been uploaded and converted to the PDF format correctly.

\section{- Approve Manuscript}

This screen provides the user with all the information gathered from the submission process. It will provide a summary of all of the data entered so far, with the option to change any of those items.

\section{Submit}

This screen is the final step of the submission process. The system will check to make sure everything is completed before the manuscript is submitted. If the manuscript is ready for submission, then there will be text that reads: "Your manuscript is ready to be submitted. Click the link below to finalize your submission." Otherwise, it will ask that you modify your submission to fulfill all of the submission requirements.

\section{Submission Fee}

A nonrefundable processing fee of USD $\$ 40$ is due upon submission. No submission fee is required for invited review article. If a fee is required, you will be asked to pay it online using credit card at the time of submission. Please note that purchase orders and bank wire transfers cannot be accepted for the processing fee. Manuscript will not be processed further unless the submission fee is received by APJAI editorial office.

\section{Manuscript Format}

Manuscripts should be type-written in English with font style Times New Roman, font size 12. All pages should be numbered consecutively at the top right-hand corner, beginning with the title page. The manuscript must display continuous line numbers $(1,2,3$, and so forth) in the left margin, beginning with the title page. (Line numbering can be added from the Page Setup or Format menu of word processing programs.) All sections of the manuscript should be typed, double-spaced with margins of at least one inch on all sides and arranged in the following order:

6.1 The title page MUST have the following information

- Title of the manuscript

- first and last names of the authors; no initials allowed unless it is a middle name

- authors and their perspective highest academic degree(s) example: Jane $\mathrm{S}$ Doe, $\mathrm{MD}, \mathrm{PhD}^{1}$, John K Watson, $\mathrm{MSc}^{2}$, Katherine Gibson, BSc ${ }^{3,4}$

- Authors' affiliation(s)

- Short running title

- Name of the corresponding author

- Address of the corresponding author including telephone, fax number and email address

- Clinical trial registration number (if applicable)

- word count for abstract

- word count for text

- Indicate total number of references

- Indicate total number of tables and figures (no more than a total of 2 figures and tables combined).

Example: 250 abstract; 3500 text; 35 references; 2 tables; 4 figures

6.2 Structured abstract with the following subheadings and not more than 250 words total (including the subheadings)

Abstract must be written in a structured format with the following headings: background; objective; methods; results; and conclusion. The major points of the article should be summarized in 150 (case reports) to 250 words (original research and review articles), in the order of their appearance in the manuscript. Abbreviations should be kept to an absolute minimum. References are not allowed in the abstract.

Keywords (at least 5 words or key phrases)

A minimum of 5 key words or brief phrases should be listed below the abstract for indexing purposes. The Medical Subject Headings (MeSH) used by the US National Library of Medicine's Index Medicus (MEDLINE) are preferred. 


\subsection{Main text}

This section must have the following headings: Introduction, Methods, Results, Discussion, and Conclusion. In the text, cite references sequentially in superscript arabic numerals, e.g., ${ }^{1,2,3}$.Tables must be numbered sequentially in the text with Arabic numerals $(1,2,3$, 4, etc). Figures must be numbered sequentially in the text with Arabic numerals (1, 2, 3,4 , etc).

\section{Introduction}

This section should state the specific purpose, research objective, or hypothesis of the study and should provide a context or background information for the study. The aims of the manuscript should be clearly stated. Papers most closely related to the issue of the study may be mentioned. The introduction should not contain either findings or conclusions.

\section{Methods}

This section should be concise but provide sufficient detail to allow the work to be repeated by others. The source of material should be given in detail, where possible. Describe the design, subjects, setting, interventions, and main outcome measures. The explanation of the experimental methods provides technical information, apparatus details, and procedures. Describe statistical methods with sufficient detail to enable a reader with access to the original data to verify the reported results. For all research studies including human subjects (excluding Case Reports) the specific IRB that has approved the research must be indicated. Additionally a statement that informed consent was obtained from all research participants must be included. The clinical trial registration number and place of registry should be informed for clinical trial studies.

\section{Results}

Describe the experimental data and results as well as the particular statistical significance of the data. Results should be presented in a logical sequence in the text, tables and figures. Excessive repetition of the same data in different forms should be avoided. The Consolidated Standards of Reporting Trials (CONSORT) statement is a set of guidelines for reporting on the methods and results of randomized and nonrandomized medical research studies and is available at the following Website: http://www. consort-statement.org.

\section{Discussion}

Provide and quantify the main outcomes of the study. The data should be interpreted concisely, without repeating data already presented in the results section. Identify limitations of the presented data including plausible explanations for discrepancies between the data and the literature, any differences not expected from the initial hypothesis presented in the introduction and a measured description of the conclusions of the study with implications for future research, biological understanding and/or clinical applications.
6.4 Acknowledgements

Conflict of interest (in the past 3 years)

Source of funding with grant numbers (if applicable) Author contributions

\subsection{References}

not more than total of 35 for original research papers not more than 70 for review papers

Vancouver style (you can download the APJAI endnotes style here (URL)

Examples

1 Rose ME, Huerbin MB, Melick J, Marion DW, Palmer AM, Schiding JK, et al. Regulation of interstitial excitatory amino acid concentrations after cortical contusion injury. Brain Res. 2002;935:40-6

2 Corporate Author Diabetes Prevention Program Research Group. Hypertension, insulin, and proinsulin in participants with impaired glucose tolerance. Hypertension. 2002;40:679-86.

Books and other monographs

1 Personal Author(s) Murray PR, Rosenthal KS, Kobayashi GS, Pfaller MA. Medical microbiology. 4th ed. St. Louis: Mosby; 2002.

2 Chapter in a Book Meltzer PS, Kallioniemi A, Trent JM. Chromosome alterations in human solid tumors. In: Vogelstein B, Kinzler KW, editors. The genetic basis of human cancer. New York: McGraw-Hill; 2002. p. 93-113.

\subsection{Figure legends}

Figure legends should be typewritten, double -spaced, and listed on a separate page after the tables. They should not appear on the figures. List all of the figure titles in the figure legend. The legends should identify the data or subject being presented and its legend are understandable without reference to the text. Figures should be professionally drawn and photographed. Colored photographs may be published and additional expense will be paid by the authors. Titles and detailed explanations belong in the figure legends, not on the figures themselves. Photomicrographs must have internal scale markers. Symbols, arrows, or letters used in the photomicrographs should contrast with the background. If a figure has been published, acknowledge the original source and submit written permission from the copyright holder to reproduce the material.

\subsection{Tables}

Tables should be numbered in the order in which they are first cited in the text with Arabic numerals $(1,2,3$, 4, etc). They should be on separate pages, one table per page. Each table should have a concise heading that makes it comprehensible without reference to the text of the article. Use horizontal lines only at the top and bottom of the table and between column headings and the body of the table. Use no vertical lines. Explain any nonstandard abbreviations in the footnote of the table, e.g., Abbreviations: CT, computed tomography; MRI, 
magnetic resonance imaging; OR, odds ratio. Footnotes in captions should appear at the bottom of the table

Please use the program's page break function to begin each section on a new page.

\subsection{Figure}

Figures (graphs, charts, photographs, and illustrations) should be numbered in the order in which they are first cited in the text.

All figures must be numbered sequentially with Arabic numerals (1, 2, 3, 4, etc). . Graphics should be saved in CMYK (cyan, magenta, yellow, black) rather than RGB (red, green, blue). The resolution specification for TIFF and EPS files is $800 \mathrm{dpi}$ for monochrome, figures that are black and white only and line shots; 250-300 dpi for gray/ CMYK or color photographs, and $600 \mathrm{dpi}$ for combinations, such as photographs labeled with letters or other markings. One figure per page

Manuscripts should be written in proper and clear English so that they are understandable to any reader who is not a specialist in the field. Authors may be requested to have the English of the manuscript checked and improved by language editing services before submission. All measurements must be given in SI units as outlined in the latest edition of Units, Symbols and Abbreviations: A Guide for Medical and Scientific Editors and Authors (Royal Society of Medicine Press, London). However, liter and molar are permitted. Abbreviations should be used sparingly and only where they reduce repetition of long, technical terms. Initially use the word in full, followed by the abbreviation in parentheses. Thereafter use the abbreviation. All manuscripts must be submitted via online at the following address: http://www.apjai-journal .org/.

\section{Article Types}

The APJAI publishes original articles, review articles, and case reports. Topics of interest include all subjects that relate to the basic and clinical aspects of allergy and immunology.

- Original Research Articles: The text of original articles should be divided into sections with the following headings in this order: Introduction, Methods, Results, Discussion, and Conclusion. The total text should not exceed 3,500 words (excluding the Abstract, References, and Figure/Table Legends). These should describe fully, but as concisely as possible, the results of original clinical and/or laboratory research. Original articles should have a structured abstract with the following headings: Background, Objective, Methods, Results and Conclusions (maximum 250 words). A minimum of 5 keywords for indexing, and no more than 35 references are required. Text should not exceed 3,500 words. Advice on appropriate sectioning of original articles can be found in the ICMJE's Uniform Requirements. Each original article may be accompanied by a combination of no more than 6 figures and tables. Original article manuscripts that are determined to significantly exceed these limits may be returned to the authors for shortening prior to review. The manuscript should be organized in the following order: title page WITH the names of the authors and affiliations (please see title page requirement mentioned above); abstract and key words; main text; acknowledgements; references; figure legends; tables (each table complete with title and footnotes), and figures. Figures should look sharp and crisp when viewed at $100 \%$ magnification. Please note that should your manuscript be accepted, the journal may request for higher resolution TIFF or EPS files.

- Review Articles: Review articles are mostly invited by the Editors. Authors interested in submitting a review article should contact the Editor-in-Chief in advance to determine the appropriateness of any proposed review prior to submitting a full manuscript. Review articles address a specific question or issue that provide an evidence-based, review on a focused topic, either clinical or basic science. Review articles should have a structured abstract (250 words or less) with the following headings Objective, Data Sources, Study Selections, Results and Conclusion, a minimum of 5 keywords, and no more than 70 references. Text should not exceed 5,000 words and should be organized into the following sections: Introduction, Body, Discussion and Conclusions.

- Case Reports: Case Reports should have an unstructured abstract of no more than 150 words, a minimum of 5 keywords, a maximum of 2 tables or figures and 20 references. The main text should not exceed 1,500 words and should be organized into the following sections: Introduction, Report of Case and Discussion. A fully structured abstract is not necessary for a Case Report. For guidance on acceptable handling of photographs and other safeguards of patient confidentiality and anonymity, refer to section II.E.1 of the ICMJE's Uniform Requirements: Patients and Study Participants.

- Short Communications: Short communications are short research articles intended to present exciting finding. Short communications are limited to 1000 words for the body of the text, 8 references and may include no more than 1 figure or 1 table. Manuscripts should be organized as described for original research article and abstract.

\section{Privacy Statement}

The names and email addresses entered in this journal site will be used exclusively for the stated purposes of this journal and will not be made available for any other purpose or to any other party. Authors must omit from their manuscripts any identifying details regarding patients and study participants, including patient names, initials, social security numbers, and hospital numbers. Patient details may be included only if they are essential for scientific purposes and the authors have obtained written informed consent from the patient, parent, or guardian for publication purposes.

\section{Publication Fees}

A sum of US $\$ 400.00$ is charged to the corresponding author of each article published in the APJAI. A pdf file will be provided to the corresponding author. In case of English editing required by reviewers, US $\$ 80.00$ is charged additionally. If the manuscript has been checked by a certified institute, please submit the certificate. Additional fee for reprints and color illustrations are charged to the authors separately. 


\section{Page Proofs}

APJAI will provide the corresponding author with galley proofs for review/correction. Corresponding authors will receive a PDF file of the typeset pages to check the copyediting before publication. Authors should make only necessary changes and return the corrected page proofs to the Editor within 3 business days.

\section{Transfer of Copyright}

All manuscripts accepted for publication become the property of APJAI. All authors must read, agree to the conditions outlined in the Authorship Form and Copyright Transfer Form. These forms must be filled out and signed as eForm. Articles cannot be published until an eForm of Authorship and Copyright Transfer Form has been received. Published articles may not be published elsewhere, in English or any other language, without the permission of the Editor-in-Chief of APJAI. 